\title{
Understanding the Unusual Looping Track of Hurricane Joaquin (2015) and Its Forecast Errors
}

\author{
WiLliam MiLler AND DA-LiN ZHANG \\ Department of Atmospheric and Oceanic Science, University of Maryland, College Park, College Park, Maryland
}

(Manuscript received 19 September 2018, in final form 5 February 2019)

\begin{abstract}
Hurricane Joaquin (2015) took a climatologically unusual track southwestward into the Bahamas before recurving sharply out to sea. Several operational forecast models, including the National Centers for Environmental Prediction (NCEP) Global Forecast System (GFS), struggled to maintain the southwest motion in their early cycles and instead forecast the storm to turn west and then northwest, striking the U.S. coast. Early cycle GFS track errors are diagnosed using a tropical cyclone (TC) motion error budget equation and found to result from the model 1) not maintaining a sufficiently strong mid- to upper-level ridge northwest of Joaquin, and 2) generating a shallow vortex that did not interact strongly with upper-level northeasterly steering winds. High-resolution model simulations are used to test the sensitivity of Joaquin's track forecast to both error sources. A control (CTL) simulation, initialized with an analysis generated from cycled hybrid data assimilation, successfully reproduces Joaquin's observed rapid intensification and southwestward-looping track. A comparison of CTL with sensitivity runs from perturbed analyses confirms that a sufficiently strong mid- to upper-level ridge northwest of Joaquin and a vortex deep enough to interact with northeasterly flows associated with this ridge are both necessary for steering Joaquin southwestward. Contraction and vertical alignment of the CTL vortex during the early forecast period may have also helped draw the low-level vortex center southward. The results indicate that for TCs developing in vertically sheared environments, improved inner-core sampling by means of cloudy radiances and aircraft reconnaissance missions may help reduce track forecast errors by improving the model estimate of vortex depth.
\end{abstract}

\section{Introduction}

Since 1990, National Hurricane Center (NHC) mean tropical cyclone (TC) 24-72-h forecast position errors have been reduced by $70 \%$ (Cangialosi and Franklin 2016), giving residents and emergency managers valuable additional time to prepare for hurricanes threatening the U.S. coast. TC intensity forecasting has shown less improvement, particularly for rapid intensification (RI) cases (Kaplan et al. 2010), characterized by minimum central sea level pressure $\left(P_{\mathrm{MIN}}\right)$ deepening rates exceeding $42 \mathrm{hPa}(24 \mathrm{~h})^{-1}$ (Holliday and Thompson 1979) or by maximum surface wind speed $\left(V_{\text {MAX }}\right)$ intensification exceeding $15 \mathrm{~m} \mathrm{~s}^{-1}(24 \mathrm{~h})^{-1}$ (Kaplan and DeMaria 2003). This discrepancy has often been explained by the fact that TCs are steered by their large-scale flow environments (George and Gray 1976; Chan and Gray 1982; Wu and Emanuel 1995), whereas TC intensification depends upon complex multiscale interactions between favorable

Corresponding author: Da-Lin Zhang, dalin@umd.edu environmental conditions, such as high sea surface temperatures (SSTs), and inner-core processes (Chen et al. 2011; Qin and Zhang 2018), some of which remain poorly understood.

Increased grid resolution, improved physics parameterizations, and more accurate initialization fields have improved the representation of environmental conditions and inner-core convective organization in operational forecast models. New observations over traditionally data-sparse oceans, which include satellite radiances and dropsondes released from National Oceanic and Atmospheric Administration (NOAA) Gulfstream-IV (G-IV) synoptic surveillance aircraft (Aberson 2010), are now being routinely assimilated into operational models. Hybrid data assimilation, which blends climatological background forecast errors with "errors of the day" extracted from multivariate forecast ensemble covariances, has been shown to improve TC track forecasts for the operational National Centers for Environmental Prediction (NCEP) Global Forecast System (hereafter GFS) model (Hamill et al. 2011) and for regional models (Wang 2011). 

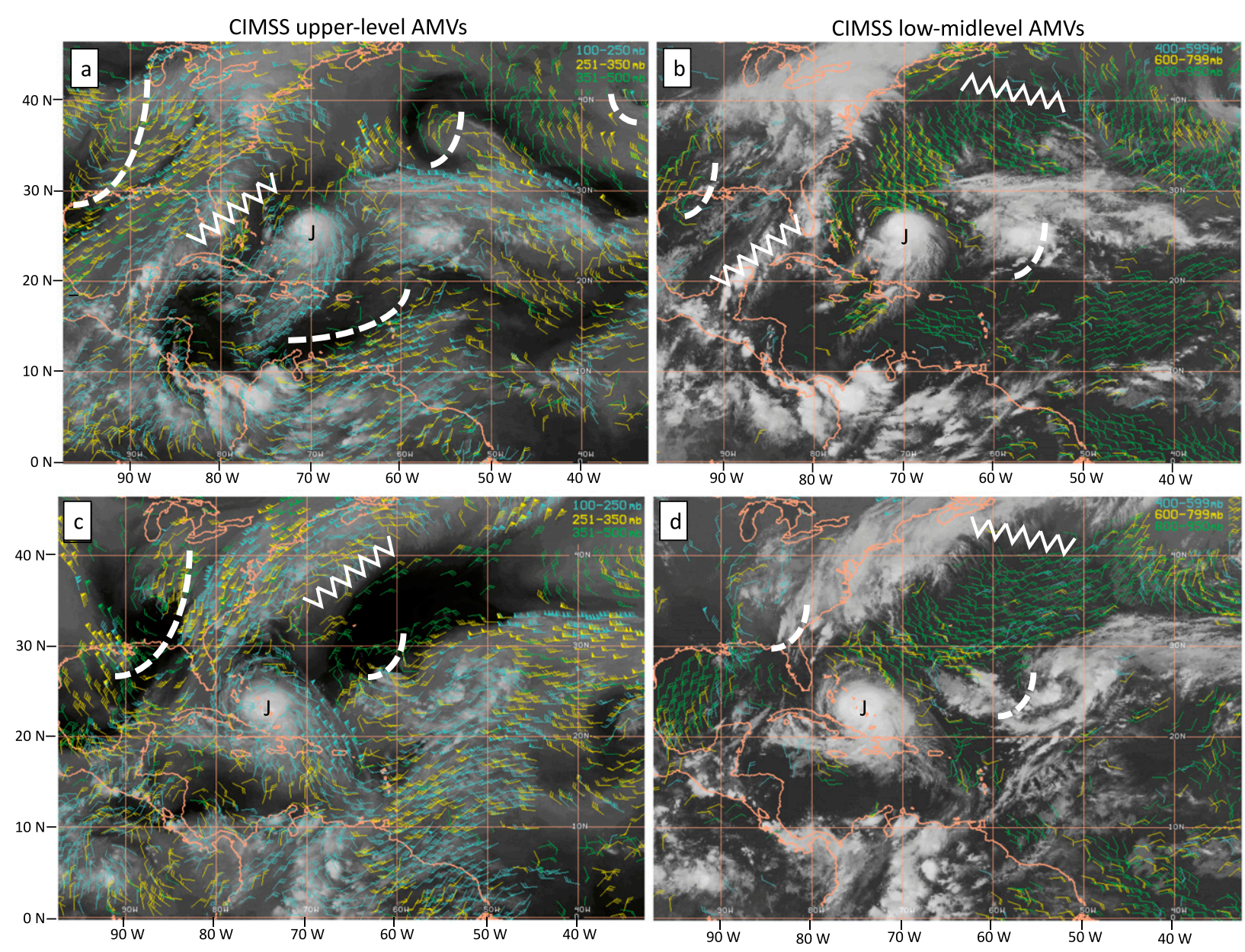

FIG. 1. Atmospheric motion vectors (AMVs) (a) upper and (b) lower-to-middle levels with vectors color coded by height valid at 0000 UTC 30 Sep 2015, superimposed over GOES-13 water vapor imagery, with Joaquin denoted by the “J”" symbol. (c),(d) As in (a),(b), but at 0000 UTC 2 Oct 2015. The AMVs are derived from the University of Wisconsin-Madison Cooperative Institute for Meteorological Satellite Studies (UW-CIMSS) and these images were obtained from http://tropic.ssec.wisc.edu/archive/.

Despite these improvements, the GFS has struggled with the track prediction of a few recent high-profile TC cases with unusual movements. Brennan and Majumdar (2011) investigated why several GFS runs failed to predict the northward turn of Hurricane Ike (2008) in the western Gulf of Mexico, and instead forecast a due-west track into the lower Rio Grande valley at 3-4 days' lead time. They traced the track errors to the model initial conditions, which overintensified the subtropical ridge north of the storm. Another notable case was Hurricane Sandy (2012), which the GFS forecast to recurve into the Atlantic for many cycles after the European Centre for Medium-Range Weather Forecasts (ECMWF) model correctly predicted a northeast U.S. landfall. Unlike Brennan and Majumdar (2011) and other previous studies (Wu and Emanuel 1995; $\mathrm{Wu}$ et al. 2004), which found that distant synopticscale features primarily controlled TC steering, Bassill
(2015) and Torn et al. (2015) both traced the GFS Sandy track forecast errors to the model representation of the near-storm environment, and specifically to the impact of latent heating from rainband convection on the intensity of a ridge north of the storm.

Hurricane Joaquin (2015) was a particularly unusual case, and its track was not well forecast by most operational models (Berg 2016, see his Fig. 9; Doyle et al. 2017). Following genesis, the storm began a climatologically rare southwestward drift toward the Bahamas. The GFS was consistent in predicting the storm to quickly curve westward and then northward, through the 1800 UTC 30 September forecast cycle, with numerous runs showing a hurricane landfall on the mid-Atlantic coast on 4 October. Notably, the ECMWF model broke ranks from the other guidance beginning with the 0000 UTC 29 September cycle, maintaining the southwestward motion longer before 


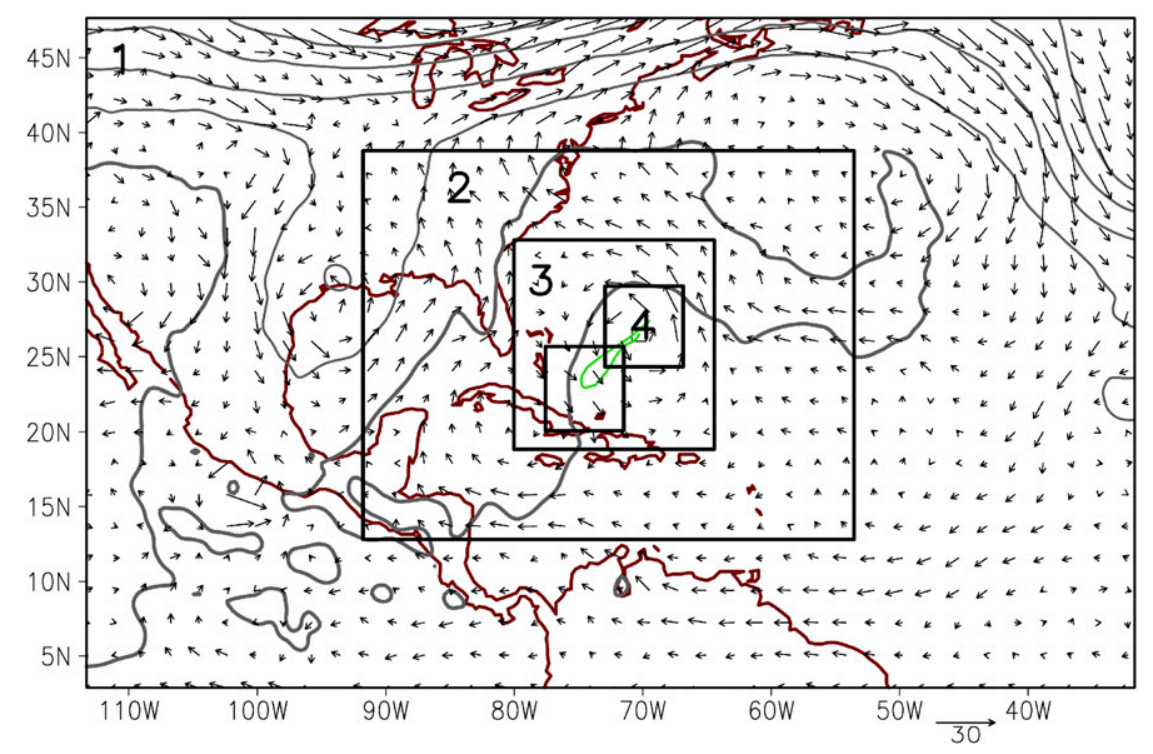

FIG. 2. Model domain configuration, superimposed over 500-hPa geopotential height (5720, $5760,5800,5840 \mathrm{~m}$, thin gray contours; $5880 \mathrm{~m}$, thick gray contour) and $700-\mathrm{hPa}$ horizontal wind vectors $\left(\mathrm{m} \mathrm{s}^{-1}\right)$, both from the 0600 UTC 29 Sep NCEP $0.25^{\circ}$-FNL. Domains $1,2,3$, and 4 have $27,9,3$, and 1-km resolutions, respectively. Domain 4 follows the storm center, with the upperright and lower-left positions shown here corresponding to the initial time and southwestern apex of the looping track, respectively. The green line shows Joaquin's best track motion over the CTL simulation period (0600 UTC 29 Sep-0000 UTC 4 Oct).

sharply recurving to the storm the northeast and missing the U.S. coast-the correct solution.

Nystrom et al. (2018, hereafter N18) simulated Joaquin using an ensemble of Weather Research and Forecasting (WRF) model forecasts initialized at 1200 UTC 29 September, and they found that the recurving members had tracked farther south during the first $24 \mathrm{~h}$, compared to the U.S. landfalling members. N18 showed how the south-tracking members were steered by stronger westerly winds later in the forecast period. This was consistent with their having moved farther south relative to a mid- to upper-level low pressure system over the southeast United States, into an environment where the cyclonic winds surrounding the low had a stronger westerly component. Key findings from this study were that (i) Joaquin's track forecast uncertainty was most sensitive to $700-\mathrm{hPa}$ winds in the near-storm environment (the 600-900-km radial band); and (ii) inner-core features did not significantly affect the steering of Joaquin. To show the latter, they reran the forecast ensemble after applying the same initial conditions within $300 \mathrm{~km}$ to every member and found that $80 \%$ of the original ensemble track spread was retained. In their analysis of the operational ECMWF ensemble initialized at 0000 UTC 30 September, Torn et al. (2018) showed that Joaquin's forecast position uncertainty, which was concentrated in the north-south direction over the first 72-h forecast, was most sensitive to ensemble member differences in the nearstorm (within $500 \mathrm{~km}$ ) steering winds that developed over the first $24 \mathrm{~h}$. This was consistent with the initialized ensemble members being located near the axis of contraction for a large-scale deformation flow, such that relatively small displacements in their meridional positions could expose them to different steering-flow regimes.

TC motion has been traditionally understood in terms of the advection of an isolated vorticity anomaly by the surrounding mean wind. Research over the past few decades has grappled with the more challenging question of how best to define the environmental flow around a TC. Chan and Gray (1982) composited rawinsonde observations surrounding a large sample of western Pacific and Atlantic TCs stratified by latitude, forward speed, size, and intensity; they found that TC motion is best correlated to winds averaged over a $5^{\circ}-7^{\circ}$ radial band in the $700-500-\mathrm{hPa}$ layer. This and earlier studies (e.g., George and Gray 1976; Gray 1977), though comprehensive, were limited by a relatively sparse global observational network. More recent case studies using airborne radar data (Marks et al. 1992) and model simulations (Liu et al. 1999) reported TC motion to be consistent with flows averaged over a much smaller region, within a $100-\mathrm{km}$ radius. Nevertheless, 
the size of the radial disk or band around a TC where the circulation interacts with the steering flow may depend on both vortex size and flow asymmetries in the near-storm environment (Holland 1983, 1984; Galarneau and Davis 2013, hereafter GD13). Other studies have emphasized the sensitivity of TC motion to the "steering layer" used for vertically averaging the environmental winds. Dong and Neumann (1986) compiled statistics from operational global analyses and showed that steering layer depth was directly proportional to TC intensity, which is consistent with stronger TCs tending to have deeper vortices. Through analysis of omega dropwindsondes released around Hurricane Josephine (1984) during a field campaign, Franklin (1990) showed that for a vertically sheared environment, a TC can be steered by a relatively narrow tropospheric layer and that these flows may not be well estimated by a deep-layered average. Together, this body of work suggests that even if the large-scale environment is well defined, TC motion may be sensitive to the vortex intensity, structure and size, particularly for complex flow environments.

The objectives of this study are to (i) obtain a successful 114-h control simulation (CTL) of Hurricane Joaquin (2015) in terms of its track, intensity and innercore structures, as validated against various observations; (ii) use the simulation, along with sensitivity tests, to further explore the causes of Joaquin's unusual southwest motion; and (iii) better understand why the operational GFS forecast struggled in predicting this motion. These objectives will be accomplished by identifying atmospheric features that were resolved differently by two representative GFS forecasts, as compared to CTL and the NCEP Final Analysis (FNL). Using these differences as a guide, we perturb the CTL initial conditions by assimilating synthetic observations and run sensitivity forecasts from these analyses. Accomplishing the above objectives will help address the following questions. First, given that the environment surrounding Joaquin was characterized by moderate vertical wind shear (VWS), with northeasterly winds more prominent in the mid- to upper troposphere (to be shown in the next section), to what extent was Joaquin's southwest motion dependent (if at all) on the vortex having sufficient vertical depth? Second, what features in Joaquin's surrounding environment influenced the steering flows? Third, did the GFS track forecast errors result from inadequate representation of the vortex, surrounding environment, or some combination of both?

The next section provides a case overview. Section 3 describes the WRF Model settings, initial condition perturbation strategy, and steering flow diagnostics

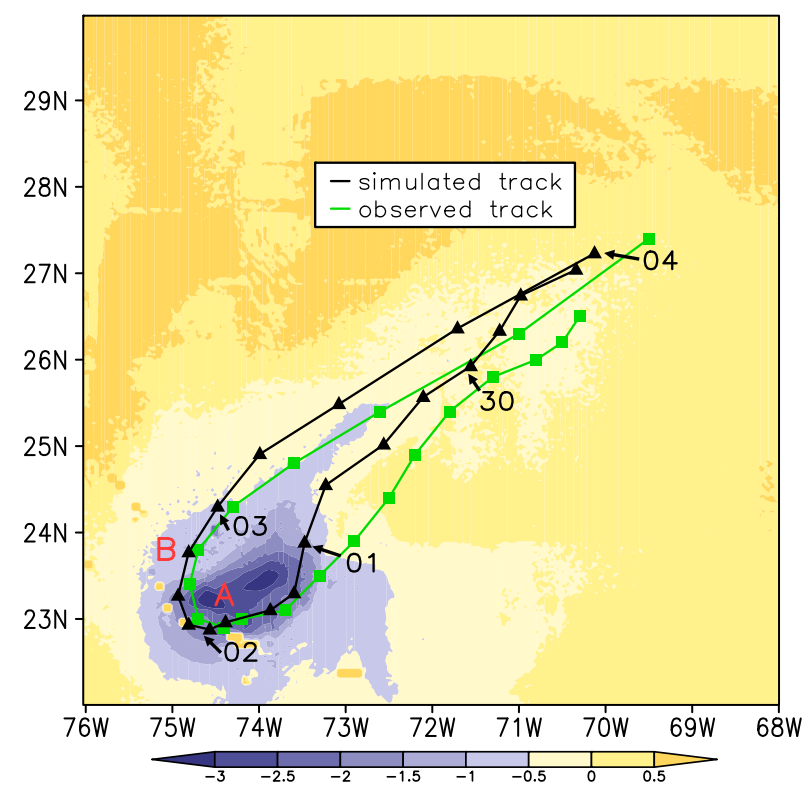

FIG. 3. Six-hourly best track (green) and model-simulated (black) Joaquin sea level center positions plotted on a subset of the 3-km domain, with the WRF parameterized SST differences (K) between 1800 UTC 2 Oct and the initial time shown in shaded colors. Number labels indicate calendar days and show 0000 UTC best track positions, with arrows pointing to the corresponding simulated positions. Letter labels "A" and "B" mark the simulated storm positions at the end of the observed RI and beginning of the observed reintensification periods, respectively.

methods. Section 4 validates CTL against observations, followed by steering flow analysis given in section 5 . Major findings and conclusions are summarized in the final section. The appendix describes the data assimilation methods used to generate the initial conditions for CTL and the WRF sensitivity tests.

\section{Case overview}

Unlike most Atlantic major hurricanes, Joaquin underwent tropical transition (Davis and Bosart 2004; Bentley et al. 2017) from an extratropical precursor disturbance (Berg 2016). Late on 26 September, a midto upper-level low that had been drifting westward across the subtropical Atlantic acquired a surface reflection about $650 \mathrm{~km}$ northeast of the central Bahamas. Although the surface center was initially displaced northwest of disorganized convection, it was designated as a tropical depression on 0000 UTC 28 September when convection developed nearby. Joaquin reached tropical storm intensity $24 \mathrm{~h}$ later, and it began a $60-\mathrm{h} \mathrm{RI}$ period $6 \mathrm{~h}$ thereafter, with its $V_{\text {MAX }}$ increasing from 18 to $61 \mathrm{~m} \mathrm{~s}^{-1}$. Although VWS of $7-12 \mathrm{~m} \mathrm{~s}^{-1}$ affected the storm during RI, high SSTs exceeding $29^{\circ} \mathrm{C}$ may have facilitated the intensification. 
Figure 1 shows how the large-scale environment surrounding Joaquin evolved as the storm moved southwestward. At 0000 UTC 30 September, when Joaquin is roughly halfway between its genesis position and its southwestern loop apex, a deep mid- to upper-level trough extends from the Great Lakes southward into the Gulf of Mexico (Figs. 1a,b). Joaquin is sandwiched between a southwest-northeast-oriented upper-level ridge on its northwest side and an upper-level trough over the southeastern Caribbean (Fig. 1a). Another upper-level low can be found well northeast of Joaquin near $35^{\circ} \mathrm{N}, 55^{\circ} \mathrm{W}$. The lower- to midlevel environment is dominated by an expensive ridge centered over the northern Atlantic southeast of Nova Scotia and another ridge over western Cuba and the Yucatan Peninsula (Fig. 1b). The cloudy region well east of Joaquin near $25^{\circ} \mathrm{N}, 55^{\circ} \mathrm{W}$ (Fig. 1b) is associated with a west-northwestward moving frontal trough that had absorbed the remnants of Tropical Storm Ida (Cangialosi 2015) several days prior. Forty-eight hours later, as Joaquin nears the southwestern loop apex, the eastern U.S. trough has dug farther south and east (Fig. 1c). Downstream of this trough, the upper-level ridge northwest of Joaquin has eroded. Meanwhile, the upper-level low northeast of Joaquin has drifted southwestward to a position near $30^{\circ} \mathrm{N}, 60^{\circ} \mathrm{W}$ (Fig. 1c), and the expansive cloudy region associated with the old frontal boundary has expanded westward toward Joaquin (Fig. 1d).

After 1800 UTC 1 October, Joaquin's intensity reached a steady state as it slowly meandered westward through the Bahamas, causing extensive destruction. Around 1200 UTC 2 October, the storm began to accelerate to the northeast, steered by southwesterly winds surrounding the eastern U.S. trough. Six hours later, Joaquin began an 18-h reintensification leading to peak intensity, with its $V_{\text {MAX }}$ increasing from 57 to $69 \mathrm{~m} \mathrm{~s}^{-1}$. The storm weakened thereafter as it encountered lowering SSTs and increasing VWS.

\section{Methodology}

\section{a. WRF Model settings}

The 114-h CTL simulation uses a two-way interactive, nonhydrostatic, quadruply nested, 27/9/3/1 km configuration of the Advanced Research core (ARW) of the Weather Research and Forecasting (WRF) model version 3.6.1 (Skamarock et al. 2008). Figure 2 shows the domain setup, where the outer 3 domains are fixed and the innermost nest moves, following the 700-hPa vortex center at 15-min intervals. The 27-, 9-, 3-, and 1-km domains, hereafter Domains 1, 2, 3, and 4, use the Mercator projection and have $(x, y)$ dimension

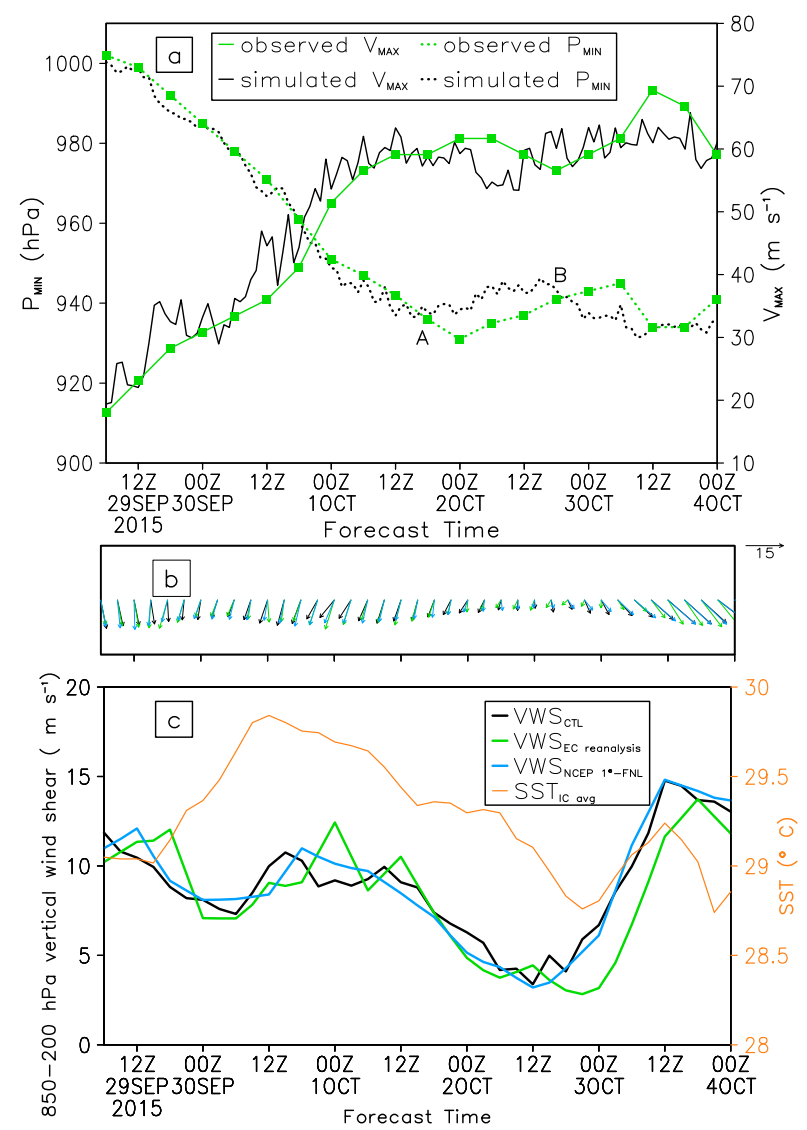

FIG. 4. Time series of (a) best track and simulated storm intensity in terms of the minimum central pressure $\left(P_{\mathrm{MIN}}\right)$ and maximum 10-m wind ( $\left.V_{\text {MAX }}\right)$, (b) VWS $\left(\mathrm{m} \mathrm{s}^{-1}\right)$, and (c) VWS magnitude with inner-core parameterized SSTs averaged within $120 \mathrm{~km}$ of the simulated storm center. Letter labels " $A$ " and " $B$ " in (a) correspond to the storm positions shown in Fig. 3. In (b),(c), black colors show model-derived VWS, while green and blue colors show VWS computed from the ECMWF reanalysis and NCEP $1^{\circ}$-FNL, respectively.

grid sizes of $(300,190),(421,322),(514,514)$, and $(601$, $601)$, respectively. The model top is set to $30 \mathrm{hPa}$, and Domains 1-4 use the 55-vertical-level configuration from Chen et al. (2011), with the highest resolution in the boundary layer and near the model top. All four domains are initialized at 0600 UTC 29 September, when Joaquin begins its 60-h RI as a tropical storm with an $18 \mathrm{~m} \mathrm{~s}^{-1} V_{\text {MAX. Initial conditions for the } 27-\text { and }}$ 9-km domains are generated using a 30-h WRF Data Assimilation (WRFDA) hybrid 3DVAR data assimilation cycle, hereafter the WRFDA-hybrid cycle (see the appendix). Neither vortex bogusing nor relocation techniques are used in generating hybrid analyses from the background WRF forecasts. The 114-h CTL forecast covers the observed RI, steady-state, and reintensification episodes. Lateral and lower boundary conditions are taken from the NCEP $1^{\circ}$ Final Analysis 

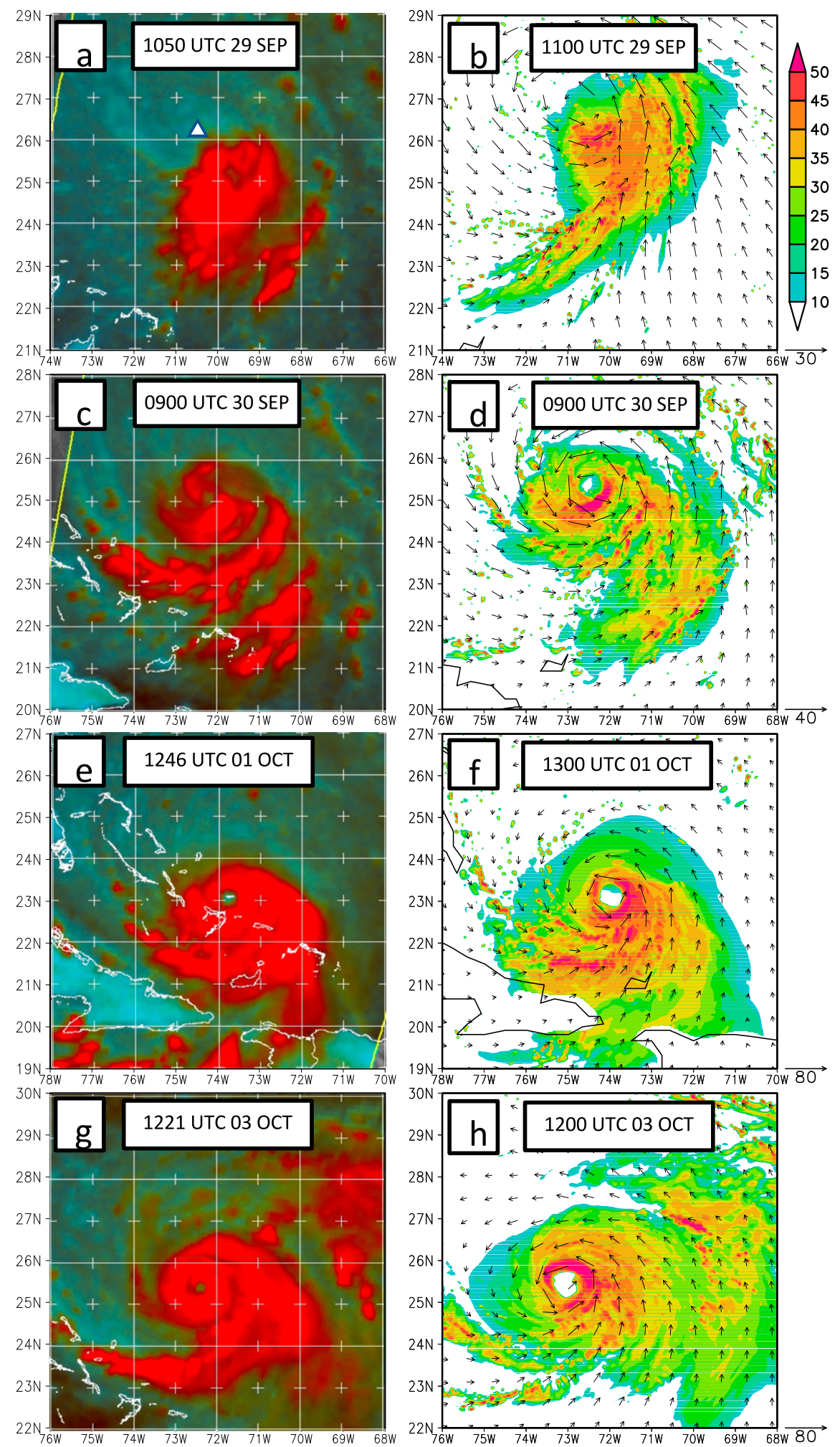

FIG. 5. (left) 85-GHz satellite imagery for (a) 1050 UTC 29 Sep, (c) 0900 UTC $30 \mathrm{Sep}$, (e) 1246 UTC 1 Oct, and (g) 1221 UTC 3 Oct, obtained from the Naval Research Laboratory TC pages (https://www.nrlmry.navy.mil/tc_pages/tc_home.html). Red colors show areas of deep convection while cyan bands indicate shallow convection and/or enhanced low-level relative humidity. (right) Model-simulated composite reflectivity (shaded, $\mathrm{dBZ}$ ) with 10-m flow vectors valid at (b) 1100 UTC 29 Sep, (d) 0900 UTC 30 Sep, (f) 1300 UTC 1 Oct, and (h) 1200 UTC 3 Oct. White triangle in (a) marks the 1200 UTC 29 Sep best track center location. 

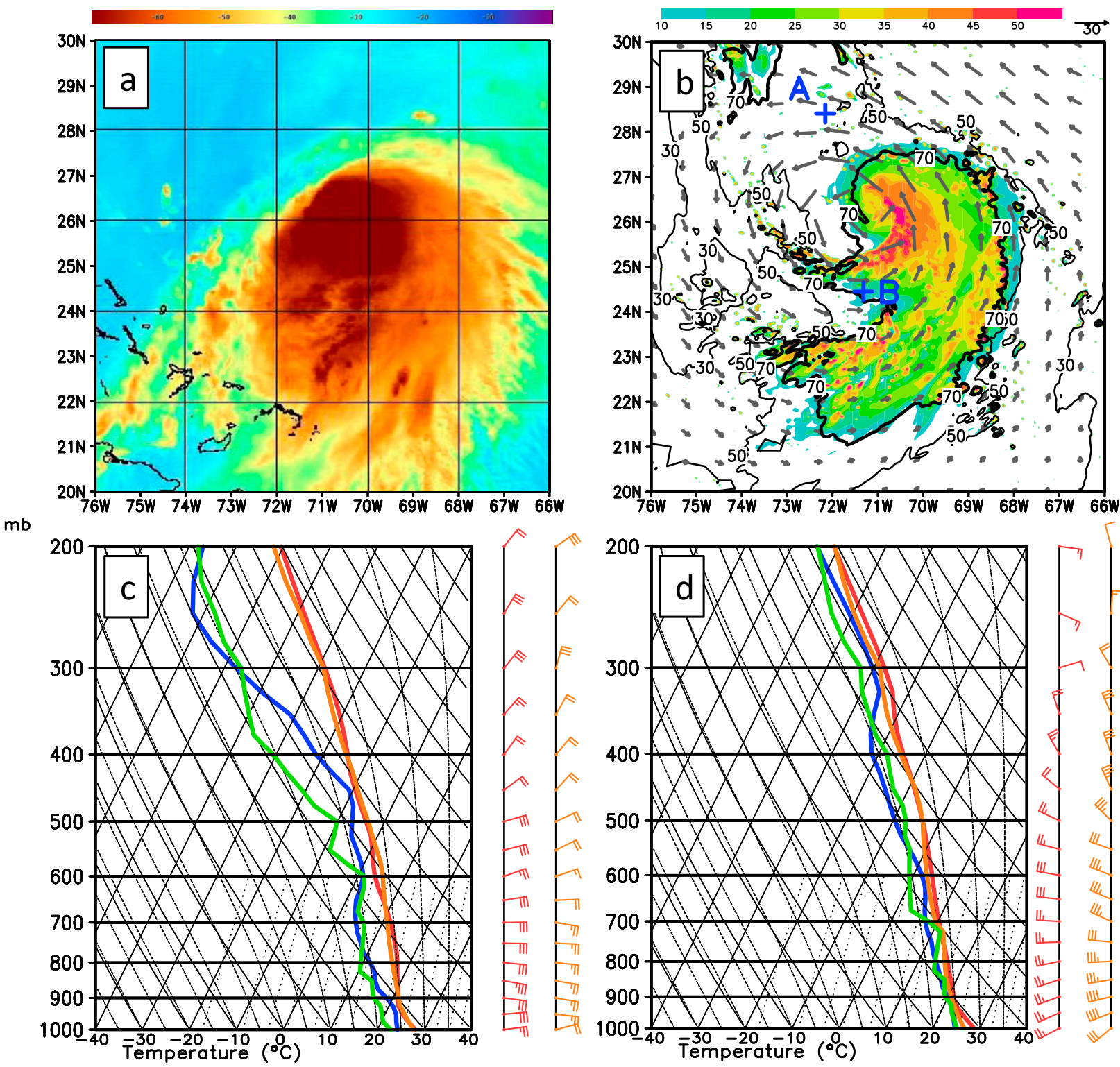

FIG. 6. (a) $G O E S$-13 water vapor satellite brightness temperature $\left({ }^{\circ} \mathrm{C}\right)$ compared against (b) the simulated composite radar reflectivity (shaded, dBZ), 700-200-hPa layer-averaged relative humidity (contoured), and 850-hPa horizontal flow vectors, with both (a) and (b) valid at 2000 UTC 29 Sep. Symbols "A" and "B" mark release positions of G-IV dropsondes falling during the 2000-2100 UTC 29 Sep period. (c),(d) Skew $T-\log p$ diagrams for dropsondes A and B, respectively, compared against model soundings at the same locations. In (c) and (d), simulated winds and temperature are plotted in red, with dropsonde winds and temperature shown in orange. Simulated (dropsonde) dewpoint is plotted in blue (green).

(hereafter $1^{\circ}$-FNL), except for the SSTs. Initial SSTs are interpolated from the NOAA daily $0.25^{\circ}$ resolution OI-SST dataset, which blends Advanced Very High Resolution Radiometer (AVHRR) and in situ observations using optimal interpolation (Reynolds et al. 2007).

We use a simple ocean mixed layer physics scheme developed for WRF-ARW (Davis et al. 2008) to parameterize the wind-induced SST cooling. This scheme neglects pressure gradients and horizontal advections but retains the Coriolis force, and it generates mixed-layer currents and upwelling-induced cooling using the model-output surface winds, an initial mixed layer depth (set to $30 \mathrm{~m}$ ) and deep-layer lapse rate (set to $0.14 \mathrm{~K} \mathrm{~m}^{-1}$ ) as inputs. Other physics options used are (i) the Thompson et al. $(2004,2008)$ microphysics scheme, which contains five hydrometeor species (rain, cloud water, cloud ice, snow, and graupel); 

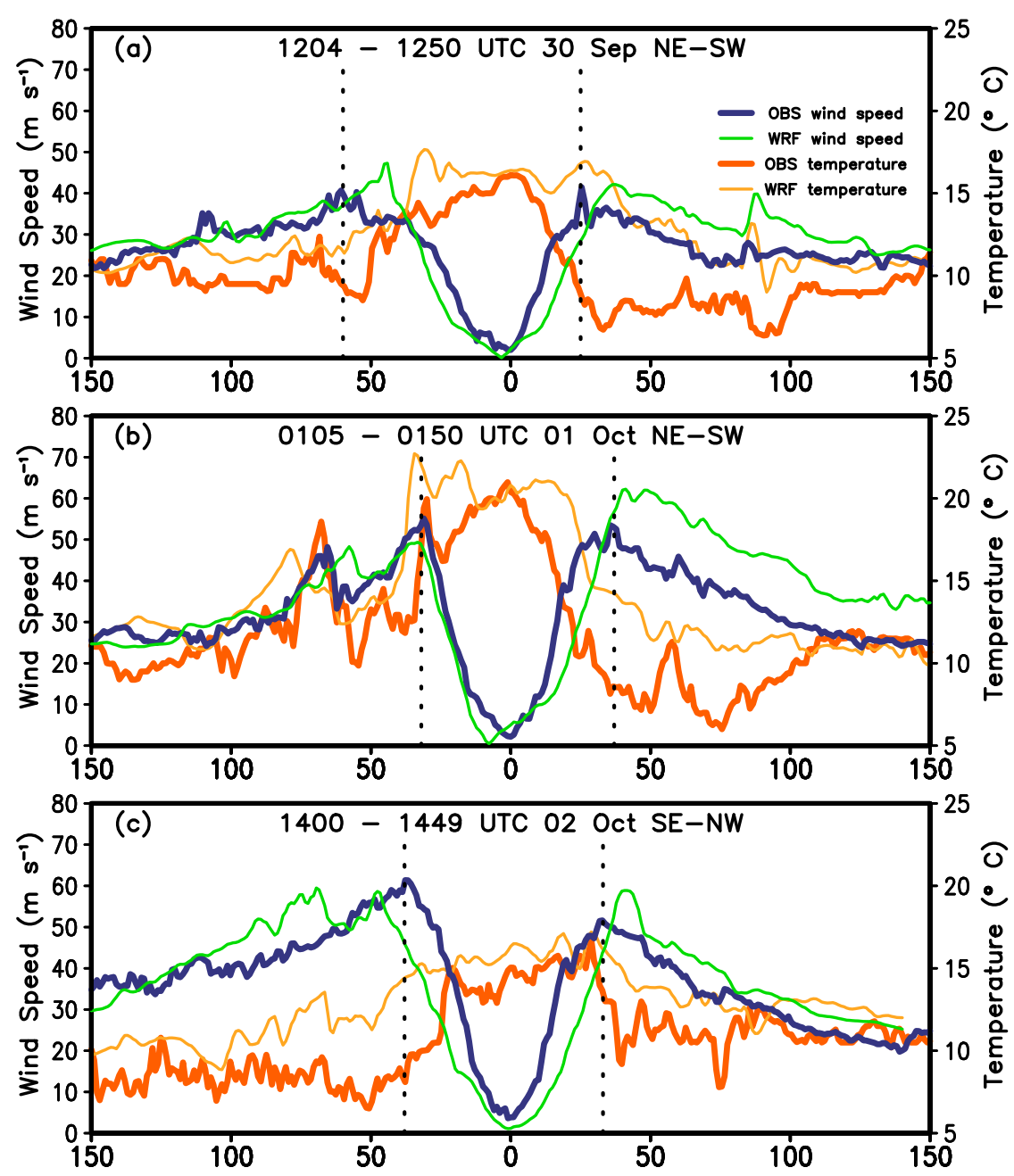

FIG. 7. (a)-(c) Air Force C-130 flight-level (700 hPa) wind speed (blue) and temperature (dark orange) recorded during transect legs at various times during Joaquin's life cycle. Simulated wind (green) and temperature (light orange) at $700 \mathrm{hPa}$ along the same transects, horizontally translated to align with the simulated storm center, are shown for comparison. Abscissa shows distances $(\mathrm{km})$ from storm center along the flight legs.

(ii) the Kain-Fritsch cumulus parameterization for the outer 2 domains (Kain and Fritsch 1990); (iii) the YSU planetary boundary layer (PBL) parameterization with the revised MM5 Monin-Obukhov surface layer physics (Hong et al. 2006); and (iv) the Rapid Radiative Transfer Model (RRTM, Mlawer et al. 1997) longwave and Dudhia (1989) shortwave radiation schemes. Surface drag coefficients are taken from Donelan et al. (2004).

We found that the most accurate track forecast could be achieved by applying analysis nudging (Stauffer and Seaman 1990) to the three fixed domains, whereby horizontal winds and temperature above the PBL are relaxed toward the $1^{\circ}$-FNL using a nudging coefficient of $3 \times 10^{-4} \mathrm{~s}^{-1}$. Through the full simulation period, nudging is applied to winds and temperature for Domains 1 and 2 and to winds for Domain 3.

\section{b. Perturbed initial condition WRF sensitivity tests}

A series of sensitivity tests is designed to perturb features in the CTL analysis that may be responsible for Joaquin's southwest motion, one at a time. WRF simulations are run from each perturbed analysis with nudging turned off, but with other model settings kept identical to CTL, using the same unperturbed NCEP $1^{\circ}$-FNL boundary conditions outside of the $27-\mathrm{km}$ domain. The CTL initial conditions are perturbed by assimilating synthetic observations, in addition to the real observations previously used for CTL, into the 
0600 UTC 29 September WRFDA-hybrid cycle (see the appendix) background forecast 27- and 9-km domains. We follow Brennan and Majumdar (2011) as a general guide, adapting their methodology to a regional data assimilation system.

To perturb large-scale features (i.e., ridges and troughs), we assimilate synthetic temperature observations at a higher level that have either +4 or $-4 \mathrm{~K}$ departures from the background temperature field. Synthetic temperature observation errors are set to $0.1 \mathrm{~K}$. The objective is to generate a temperature anomaly that modifies the geopotential height field above and below through hydrostatic adjustment both in the data assimilation, though the multivariate hybrid background error covariances, and in the subsequent WRF integration. For example, assimilation of $300-\mathrm{hPa}$ temperature observations with $-4 \mathrm{~K}$ departures from the background would be expected to reduce thicknesses in the layer surrounding $300 \mathrm{hPa}$, causing heights over a deeper layer below to rise. These tests, to be described in section $5 b$, are named using the prefixes PERT-R or PERT-T, with the letters $\mathrm{R}$ and $\mathrm{T}$ indicating whether a ridge or trough is to be perturbed.

An additional sensitivity test, PERT-V, tests the impact of a weakened vortex on Joaquin's track. Two types of synthetic vertical soundings, in addition to real observations, are assimilated into the WRFDA-hybrid cycle background forecast: (i) a single column, centered on Joaquin's upper-level warm core, where the background temperature is reduced by $6 \mathrm{~K}$ every $50 \mathrm{hPa}$ over the 500-200-hPa layer, and (ii) concentric rings, centered on the best track fix, where the background relative humidity is reduced by $50 \%$ every $50 \mathrm{hPa}$ over the 1000-700-hPa layer. Observation errors for (i) and (ii) are set to $0.1 \mathrm{~K}$ and $10 \%$, respectively.

\section{c. Steering flow diagnostics}

For a given pressure level $p$, we define the environmental winds within a disk bounded by radius $r$ as the area-averaged horizontal flows that remain after removing the symmetric TC vortex. Following Hanley et al. (2001), we compute the modeled environmental wind $\mathbf{v}_{\mathrm{env}, m}(r, p)$ vector components after interpolating the Cartesian winds to cylindrical coordinates, using

$$
\begin{aligned}
& u_{\mathrm{env}, m}(r, p)=\frac{1}{A} \sum_{i=1}^{I_{r}}\left[\frac{\overline{u_{m}}(p)_{i-1}+\overline{u_{m}}(p)_{i}}{2}\right] A_{i}, \\
& v_{\mathrm{env}, m}(r, p)=\frac{1}{A} \sum_{i=1}^{I_{r}}\left[\frac{\overline{v_{m}}(p)_{i-1}+\overline{v_{m}}(p)_{i}}{2}\right] A_{i},
\end{aligned}
$$
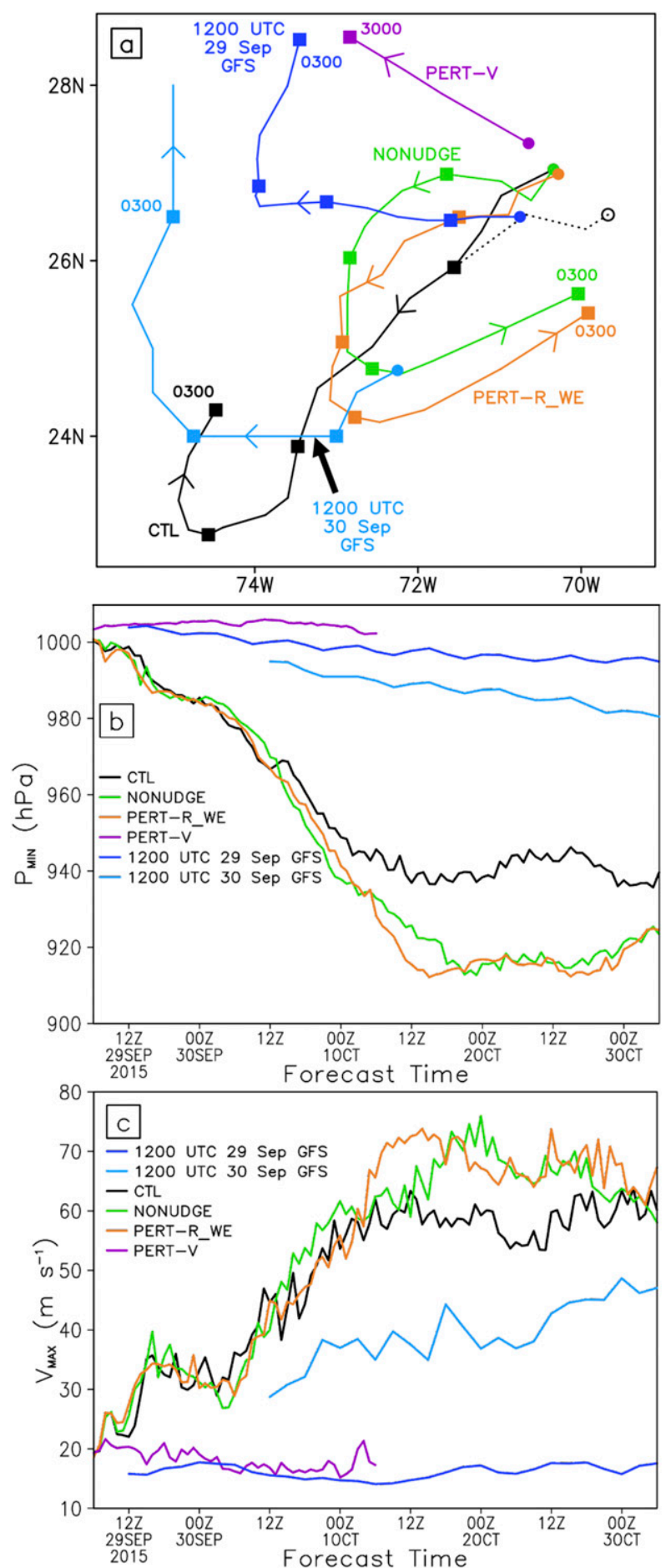

FIG. 8. (a) Track forecasts for CTL and the initial condition sensitivity WRF runs, with the 1200 UTC 29 Sep and 1200 UTC 30 Sep operational GFS forecasts also shown. Closed circles show initial sea level center positions and squares show sea level center positions for each subsequent 0000 UTC time. Time labels are given in ddhh format, where dd and hh denote the two-digit calendar day and hour, respectively. The open circle and dotted line show the initial position and track of the CTL upper-level center prior to the vortex becoming vertically aligned. (b),(c) Minimum central pressure $\left(P_{\mathrm{MIN}}\right)$ and maximum 10-m wind ( $\left.V_{\text {MAX }}\right)$ forecasts are shown. 
where $u_{m}$ and $v_{m}$ are the interpolated Cartesian winds, overbars denote azimuthal averages, $i$ is the radial index, $I_{r}$ indexes vortex removal radius $r, A_{i}$ is the annular area between radial indices $i$ and $i-1$, and $A=\pi r^{2}$. We take the NCEP $0.25^{\circ}$ Final Analysis $\left(0.25^{\circ}\right.$-FNL) as a proxy for the true atmosphere and compute the "observed" environmental wind $\mathbf{v}_{\mathrm{env}, o}(r, p)$ using (1) and (2), with the $m$ subscripts replaced with $o$. GFS forecast and $0.25^{\circ}$-FNL horizontal winds are regridded to a storm-centered Cartesian regional domain with $25-\mathrm{km}$ horizontal resolution. Steering flow analysis for WRF simulations is performed on the 9-km resolution domain. We define the vortex center at every pressure level as the gridpoint surrounded by the largest circulation, or area-averaged vorticity, within a $90-\mathrm{km}$ radius, ${ }^{1}$ after Cavallo et al. (2013). All computed centers are visually checked against horizontal wind and vorticity fields and corrected if necessary.

Vertical wind shear vector components are computed by setting $r=500 \mathrm{~km}$ and differencing the environmental winds between the 200- and $850-\mathrm{hPa}$ levels:

$$
\begin{aligned}
& u_{\mathrm{VwS}, m}=u_{\mathrm{env}, m}(r, 200 \mathrm{hPa})-u_{\mathrm{env}, m}(r, 850 \mathrm{hPa}), \\
& v_{\mathrm{VwS}, m}=v_{\mathrm{env}, m}(r, 200 \mathrm{hPa})-v_{\mathrm{env}, m}(r, 850 \mathrm{hPa}) .
\end{aligned}
$$

We adopt the methodology developed by GD13 and define the optimal steering flow as the volumeaveraged environmental wind that minimizes the vector difference from the simulated storm speed $\mathbf{c}_{m}$. This difference, which we call the steering flow residual, results from errors in computing the environmental wind and storm speed, as well as from storm-scale processes such as the redistribution of convection relative to the storm center in response to vertical shear. For model output, we test 72 combinations of vortex removal radii, every $100 \mathrm{~km}$ ranging from 200 to $700 \mathrm{~km}$, and steering layer top levels above $p_{b}=850 \mathrm{hPa}$, every $50 \mathrm{hPa}$ up to $250 \mathrm{hPa}$ to find the optimal radius $r_{m}$ and steering layer top level $p_{t, m}$ yielding the smallest steering flow residual. The optimal steering flow $\mathbf{V}_{\text {opt }, m}$ is the pressure-weighted vertically averaged environmental wind vector:

$$
\begin{aligned}
& U_{\mathrm{opt}, m}=\frac{1}{p_{b}-p_{t, m}} \int_{p_{t, m}}^{p_{b}} u_{\mathrm{env}, m}\left(r_{m}, p\right) d p, \\
& V_{\mathrm{opt}, m}=\frac{1}{p_{b}-p_{t, m}} \int_{p_{t, m}}^{p_{b}} v_{\mathrm{env}, m}\left(r_{m}, p\right) d p .
\end{aligned}
$$

The optimal observed steering flow $\mathbf{V}_{\text {opt }, o}$, radius $r_{o}$, and steering layer top level $p_{t, o}$ can be similarly found for the $0.25^{\circ}$-FNL using $\mathbf{v}_{\text {env, } o}(r, p)$ and the observed storm speed $\mathbf{c}_{o}$. To compute $\mathbf{c}_{m}\left(\mathbf{c}_{o}\right)$, 24-h centered differences of 850 -hPa center (NHC best track) fixes are used. Thus, we can write the steering flow residuals for model and $0.25^{\circ}$-FNL data as

$$
\begin{aligned}
& \mathbf{V}_{\text {resid }, m}=\mathbf{V}_{\mathrm{opt}, m}-\mathbf{c}_{m} \\
& \mathbf{V}_{\text {resid }, o}=\mathbf{V}_{\mathrm{opt}, o}-\mathbf{c}_{o} .
\end{aligned}
$$

Environmental wind profiles are evaluated at the optimal radius, with

$$
\begin{aligned}
& \mathbf{v}_{m}(p)=\mathbf{v}_{\mathrm{env}, m}\left(r_{m}, p\right) \\
& \mathbf{v}_{o}(p)=\mathbf{v}_{\mathrm{env}, o}\left(r_{o}, p\right) .
\end{aligned}
$$

Finally, we define

$$
\hat{\mathbf{v}}_{m}(p)=\mathbf{v}_{\mathrm{env}, m}\left(r_{o}, p\right),
$$

which enables us to compare the model-output and $0.25^{\circ}$-FNL environmental wind profiles for the same disk region surrounding their respective centers.

Model steering flow errors are quantified using the diagnostic equation derived in GD13:

$$
\begin{aligned}
\mathbf{V}_{\mathrm{opt}, m}-\mathbf{V}_{\mathrm{opt}, o}= & \frac{1}{p_{b}-p_{t, o}} \int_{p_{t, o}}^{p_{b}}\left(\hat{\mathbf{v}}_{m}-\mathbf{v}_{o}\right) d p+\frac{1}{p_{b}-p_{t, m}} \int_{p_{t, m}}^{p_{b}}-\left(\hat{\mathbf{v}}_{m}-\mathbf{v}_{m}\right) d p+\frac{1}{p_{b}-p_{t, m}}\left[\int_{p_{t, o}}^{p_{b}}\left(\frac{p_{t, m}-p_{t, o}}{p_{b}-p_{t, o}}\right) \hat{\mathbf{v}}_{m} d p\right. \\
& \left.+\int_{p_{t, m}}^{p_{t, o}} \hat{\mathbf{v}}_{m} d p\right]+\mathbf{V}_{\text {resid }, m}+\mathbf{V}_{\text {resid }, o}
\end{aligned}
$$

\footnotetext{
${ }^{1}$ The $850-\mathrm{hPa}$ center is located first, using the geopotential

${ }^{1}$ The $850-\mathrm{hPa}$ center is located first, using the geopotential
height centroid as a first guess, and the higher-level centers are then found in order of increasing height, using the previously found center as the first guess.
}

The left-hand side approximates the error in simulated TC motion, provided that $\mathbf{V}_{\text {resid, } m}$ and $\mathbf{V}_{\text {resid, } o}$ are both small. The right-hand side terms from left to right are the environmental wind error, vortex removal radius error, vortex depth error, and residuals 

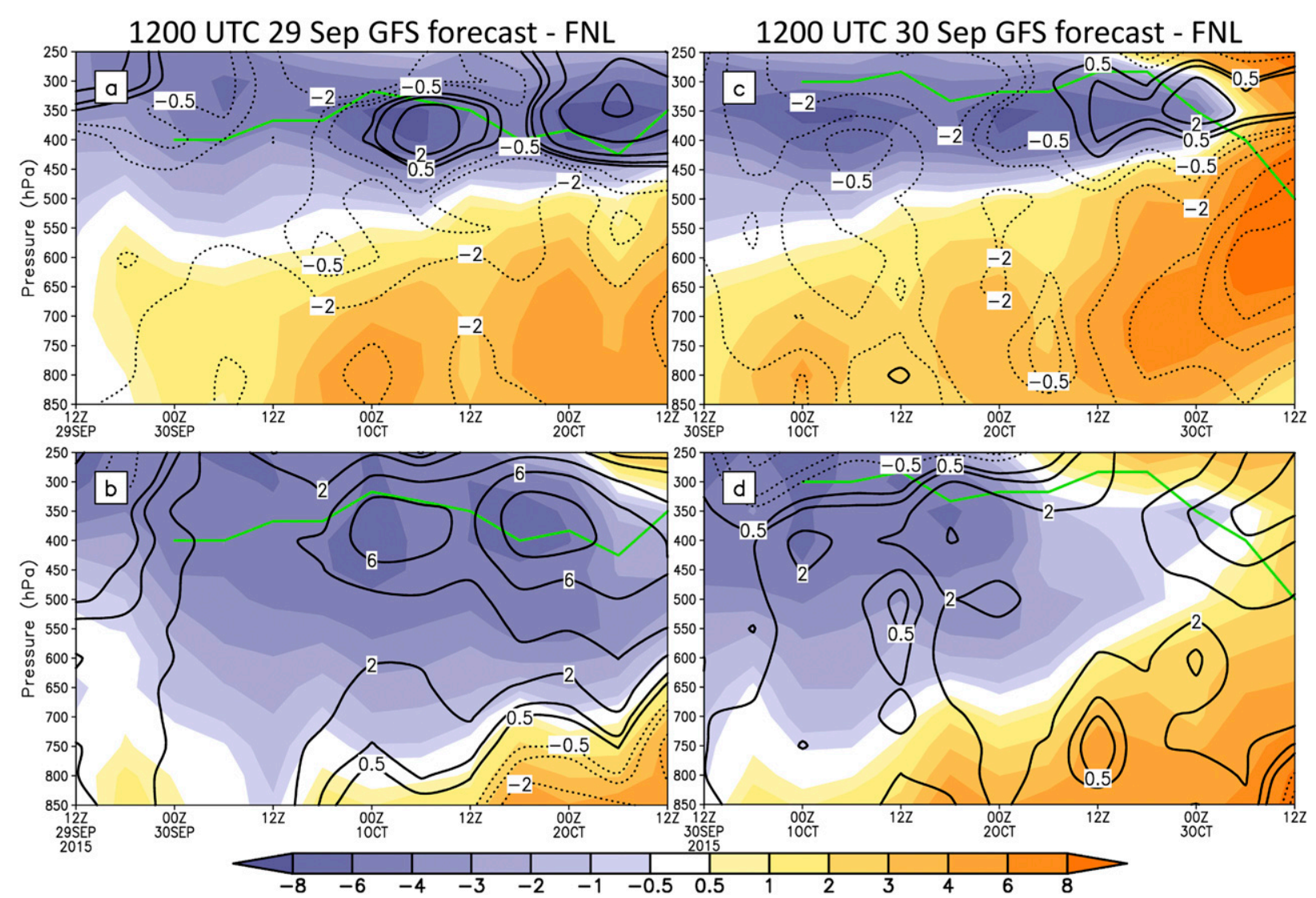

FIG. 9. (a) Environmental $u$-wind profile time series for the $0.25^{\circ}$-FNL (shaded, $\mathrm{m} \mathrm{s}^{-1}$ ), with differences in environmental $u$ winds from the 1200 UTC 29 Sep cycle operational GFS forecast (GFS $-0.25^{\circ}$-FNL; dot contoured for $-8,-6,-4,-2,-1$, $-0.5 \mathrm{~m} \mathrm{~s}^{-1}$, and solid contoured for $0.5,1,2,4,6,8 \mathrm{~m} \mathrm{~s}^{-1}$ ). Green line denotes the top of the GFS forecast optimal steering layer, computed as a running mean over the 12-h period centered on the current time. (b) As in (a), but for environmental $v$ winds. (c),(d) As in (a),(b), but for differences between the $0.25^{\circ}$-FNL and the 1200 UTC 30 Sep cycle operational GFS. Environmental winds for (a),(b), and (c),(d) are computed using 400 and 500-km vortex removal radii, respectively, corresponding to the mean optimal steering radii for the respective GFS forecasts over the periods shown. Note that an optimal steering depth is not shown for the first 12-h GFS forecast periods because this calculation uses 24-h centered differences in forecast storm position.

in the model and observations, respectively. The first term approximates the error in model-output environmental winds, averaged over the observed optimal steering volume. The removal radius and vortex depth errors arise from the optimal steering flow calculation yielding different vortex removal radii and steering layer depths, respectively, for the model and the true storm. Physically, the removal radius (vortex depth) errors are related to model misrepresentation of vortex size (depth) when the environmental winds vary substantially in the horizontal (vertical) direction. For example, a northerly directed vortex depth error would result when a model simulates an environment with northerly steering flow reasonably well but fails to develop a vortex deep enough to interact with the upper-level northerly steering winds.

\section{Validation of the CTL simulation}

Before addressing the causes of Joaquin's unusual track, it is necessary to validate CTL against observations. Figure 3 compares the CTL forecast track to the NHC best track positions. The southwestward motion toward the Bahamas, slow clockwise motion around the loop apex, and recurvature are all reproduced. The observed RI is well captured by CTL (Fig. 4a). The end of simulated RI (1200 UTC 1 October) coincides with significant slowing in the storm's forward speed, by which time the Davis et al. (2008) parameterization has cooled mean inner-core SSTs along and to the right of the simulated track by $\sim 0.5^{\circ} \mathrm{C}$ relative to $24 \mathrm{~h}$ previously (Fig. $4 \mathrm{c}$ ). Observational and modeling studies have shown that a $1^{\circ} \mathrm{C}$ reduction in inner-core SSTs can induce substantial 

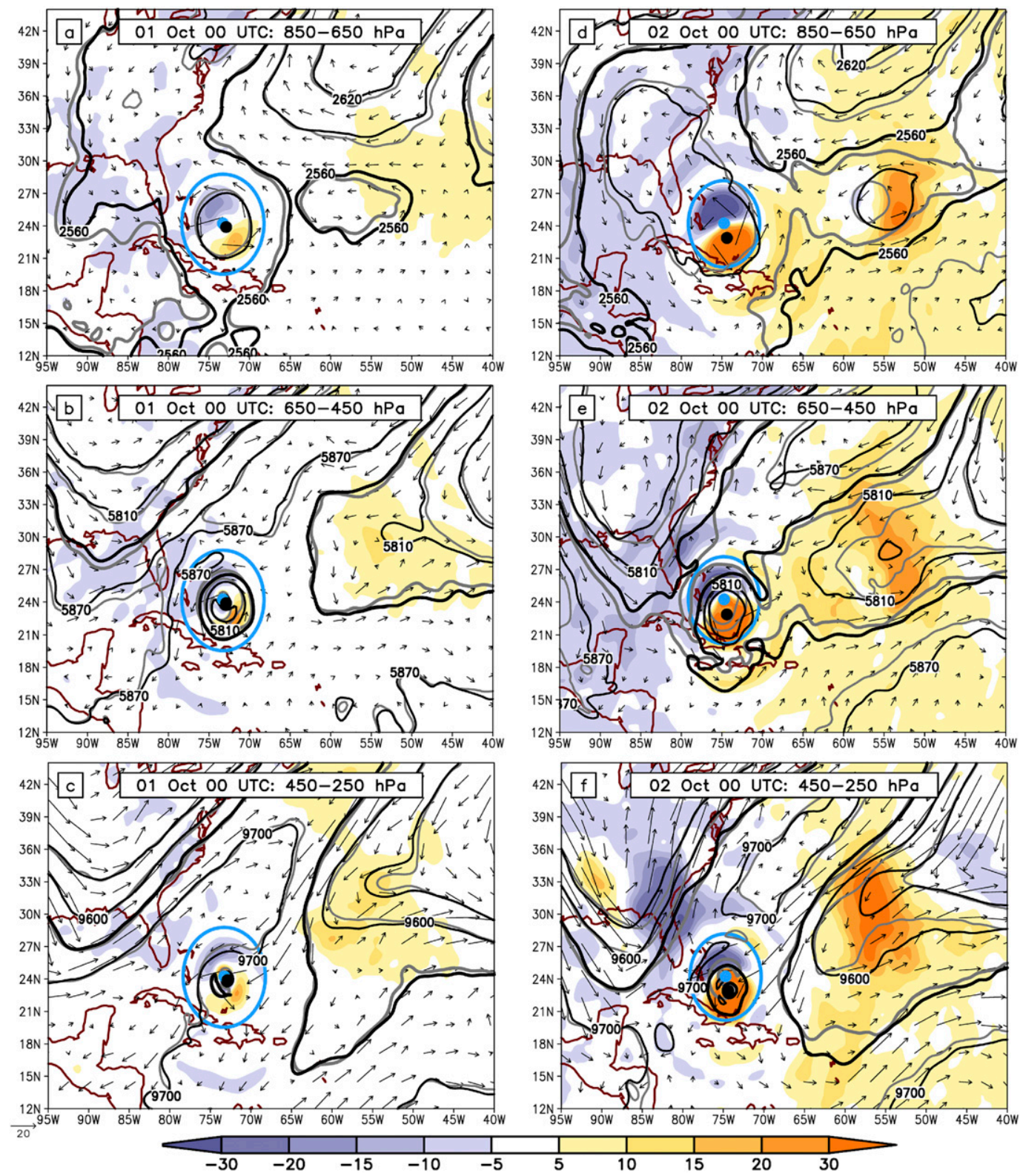

FIG. 10. (a) Geopotential height difference (m, shaded) between the 1200 UTC 30 Sep cycle operational GFS 12-h forecast and the NCEP $0.25^{\circ}$-FNL valid at the same time (GFS - FNL), computed at each diagnostic pressure level and then averaged over the 850-650-hPa layer. FNL and GFS-forecast 750-hPa geopotential height for this time are contoured in black and gray, respectively, over the range 2530, 2560, 2590, and $2620 \mathrm{~m}$. FNL horizontal winds $\left(\mathrm{m} \mathrm{s}^{-1}\right)$ are also shown. Black (blue) circles denote the best track (GFS forecast) storm centers. (b) As in (a), but for height differences averaged over the 650-450-hPa layer, with 500-hPa height (contoured at 5780, 5810, $5840,5870 \mathrm{~m}$ ) and winds. (c) As in (a), but for height differences averaged over the 450-250-hPa layer, with 300-hPa height (contoured at 9550, 9600, 9650, $9700 \mathrm{~m}$ ) and winds. (d)-(f) As in (a)-(c), but for the 1200 UTC 30 Sep cycle operational GFS 36 -h forecast and $0.25^{\circ}$-FNL valid at the same time. Circles in (a)-(c) and (d)-(f) denote 500 and 433-km GFS optimal steering radii computed for the times shown. Thickened contours emphasize the troughs approaching Joaquin from the northwest and east.

weakening or preclude further intensification in an otherwise favorable environment, due to lowered surface enthalpy fluxes (Cione and Uhlhorn 2003; Zhu and Zhang 2006). The simulated $P_{\text {MIN }}$ begins to reintensify around 1200 UTC 2 October, although the intensification rate is modest compared to the observations. As the storm accelerates northeastward away from its self-generated "cold pool", local SSTs 


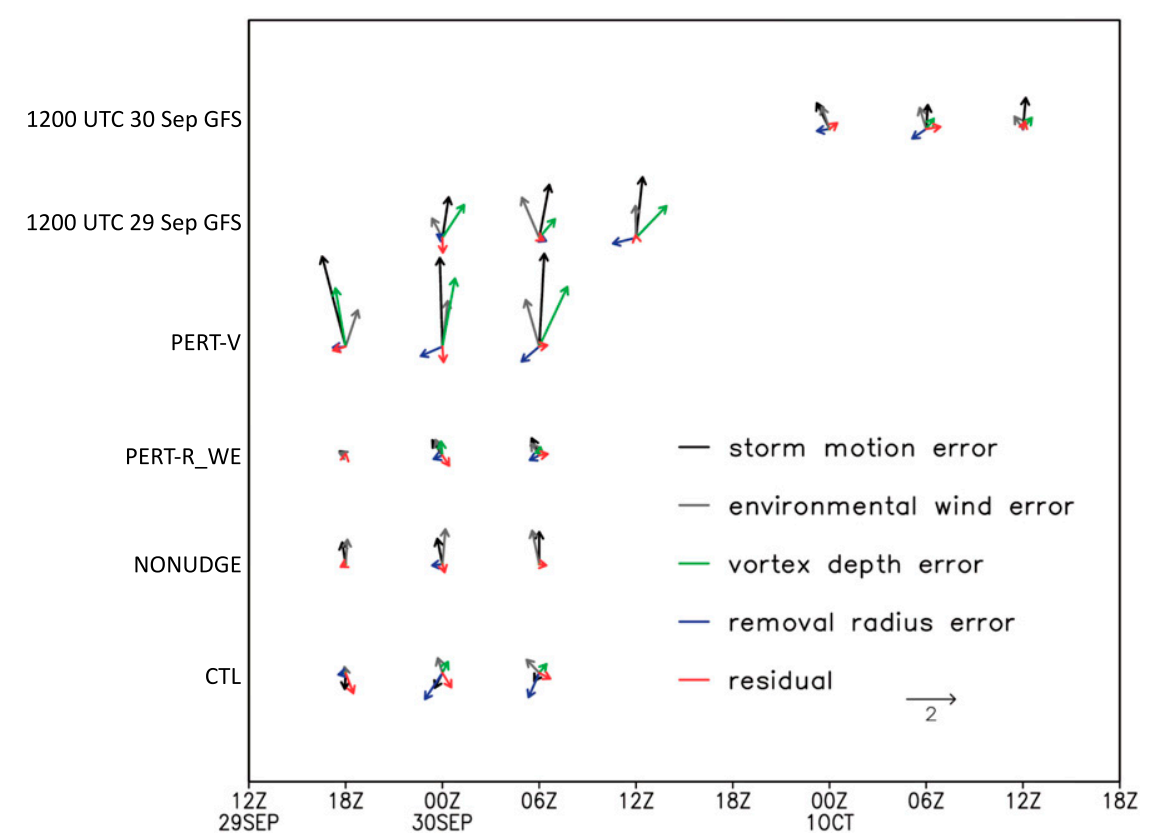

FIG. 11. Time series of Galarneau and Davis (2013) TC motion equation error budget terms $\left(\mathrm{m} \mathrm{s}^{-1}\right)$ for selected model forecasts, with $u$ and $v$ components combined into vector form.

are warming while northwesterly VWS is increasing (cf. Figs. 3 and 4), as an upper-level low approaches from the east (not shown).

Figure 5 compares model-simulated radar reflectivity against microwave satellite imagery for a few selected times. Five hours after initialization, the inner core remains highly asymmetric, with convection displaced south of the low-level circulation center in both the observations and the simulation (Figs. 5a,b). Previous TC modeling and observational studies have shown that RI can be accompanied by an increasingly axisymmetric inner-core structure, with convection wrapping around the center (Rogers 2010; Chen et al. 2011; Zagrodnik and Jiang 2014; Rogers et al. 2015; Rios-Berrios et al. 2016; Fischer et al. 2018; RiosBerrios et al. 2018); a similar trend can be seen for Joaquin as RI progresses (Figs. 5c-f). Nevertheless, a balanced vortex response to the northerly VWS (Jones 1995; Wang and Holland 1996; Molinari et al. 2006; Nguyen and Molinari 2015) may have helped focus vigorous convection south of the storm center throughout RI (Figs. 5a-f). Dry air at the mid- to upper levels north of the storm may have further suppressed convection in that region (Figs. 6a-c). The environment south of the eyewall, on the other hand, is nearly saturated from the PBL to the upper troposphere (Fig. 6d). Some erosion of the northern eyewall occurs during steady-state (not shown), and reintensification is accompanied by a reinvigoration of eyewall convection and the development of new convection underneath the upper-level low to Joaquin's northeast (Figs. 5g,h).

Zooming into the inner core, we next examine flight-level wind and temperature profiles from the U.S. Air Force Reserve 53rd Weather Reconnaissance Squadron C-130 aircraft missions flown during Joaquin's southwest movement period, and compare them to cross sections taken through CTL (Fig. 7). The model reproduces the sharpening tangential wind profile and low-level eye warming observed during RI (Figs. 7a,b), and also the weakened lowlevel warm anomaly for the steady-state period (Fig. 7c).

\section{Steering flow analysis}

\section{a. GFS forecast errors}

We begin our steering-flow analysis by examining two operational GFS forecasts, initialized at 1200 UTC on 29 and 30 September, respectively, and diagnosing their track error sources using the GD13 budget equation. When analyzing the large-scale steering environment, we use the $0.25^{\circ}$-FNL rather than CTL as the "truth dataset" because, as discussed in section 3a, analysis nudging was used to force winds in the outer three CTL domains toward the $1^{\circ}$-FNL. The 1200 UTC 

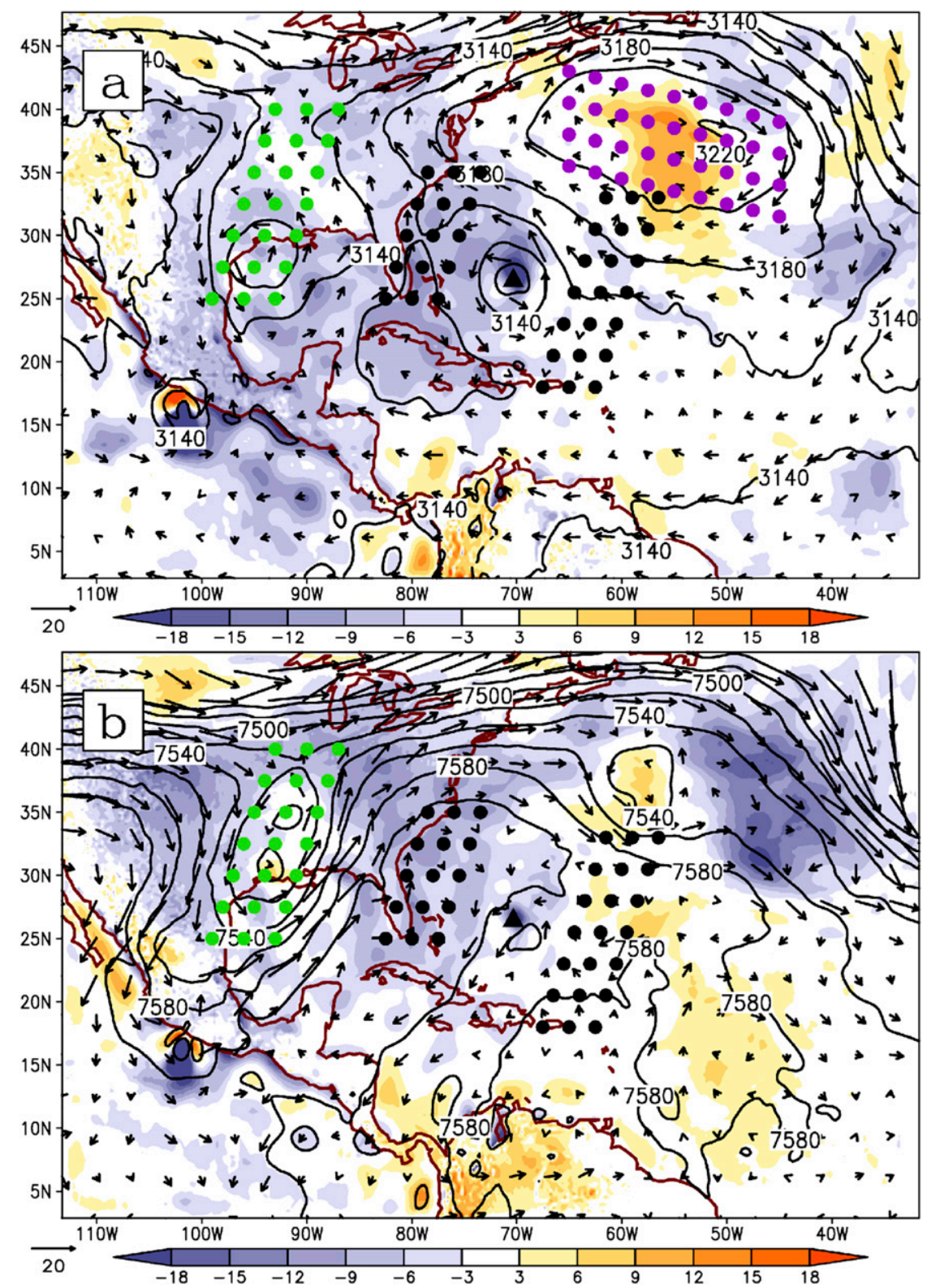

FIG. 12. (a) Geopotential height differences between the 0600 UTC 29 Sep NCEP $0.25^{\circ}$-FNL and the CTL initial conditions (CTL - FNL), computed at each pressure level and then averaged over the 850-600-hPa layer (shaded, m) with 700-hPa FNL geopotential height (contoured, $\mathrm{m}$ ) and horizontal flow vectors $\left(\mathrm{m} \mathrm{s}^{-1}\right)$. (b) As in (a), but for geopotential height differences averaged over the 600-250-hPa layer, with 400-hPa FNL geopotential height and winds. Black triangle denotes the 0600 UTC 29 Sep best track Joaquin position. Black, purple, and green dots show the synthetic observation locations for the PERT-R_WE, PERT-R_ATL, and PERT-T experiments.

29 September GFS forecast, initialized $6 \mathrm{~h}$ after CTL, tracks the low-level center westward for $48 \mathrm{~h}$ before turning it sharply north and eventually northeast into the western Atlantic (Fig. 8a). It also fails to intensify Joaquin (Figs. 8b,c). Whereas the CTL upper-level center becomes aligned with the surface center within
$18 \mathrm{~h}$ (Fig. 8a), the 29 September GFS upper-level center drifts slowly west-southwest during the first $60 \mathrm{~h}$, maintaining $\sim 200 \mathrm{~km}$ of separation from the low-level center (not shown). The GFS vortex initialized $24 \mathrm{~h}$ later (i.e., at 1200 UTC 30 September) is now vertically aligned (not shown), despite being $10 \mathrm{~m} \mathrm{~s}^{-1}$ weaker in 
TABLE 1. Summary of the perturbed initial condition WRF sensitivity tests. Synthetic observation pressure levels and perturbation strengths are shown here for each experiment, and their locations are shown in Figs. 12 and 13. For all layer soundings, observations are assimilated every $50 \mathrm{hPa}$.

\begin{tabular}{llccc}
\hline \hline \multicolumn{1}{c}{ Name } & \multicolumn{1}{c}{ Objective } & Level (hPa) & Type & Strength \\
\hline PERT-R_W & Strengthen 850-300-hPa layer ridging northwest of Joaquin & 300 & Temperature & $-4 \mathrm{~K}$ \\
PERT-R_E & Weaken 850-300-hPa layer ridging southeast of Joaquin & 300 & Temperature & $4 \mathrm{~K}$ \\
PERT-R_WE & Combine the impacts of PERT-R_W and PERT-R_E & 300 & Temperature & -4 and 4 K \\
PERT-R_ATL & Weaken 850-600-hPa layer ridging in north-central Atlantic & $600-400$ & Temperature & $4 \mathrm{~K}$ \\
PERT-T & Weaken eastern U.S. trough over 850-300-hPa layer & 300 & Temperature & $-4 \mathrm{~K}$ \\
PERT-V & Weaken TC Joaquin vortex & $500-200$ & Temperature & $-6 \mathrm{~K}$ \\
& & $1000-700$ & Relative humidity & $-50 \%$ \\
\hline
\end{tabular}

$V_{\text {MAX }}$ compared to the best track data (Figs. 8b,c). Although it initially tracks southwestward, it ceases this motion $24 \mathrm{~h}$ earlier than the observed storm, turning due west and then north (Fig. 8a), eventually making landfall on the North Carolina coast (not shown).

Figure 9 plots time series of the $0.25^{\circ}$-FNL environmental steering wind $u$ and $v$ profiles, along with their differences from the 1200 UTC 29 and 30 September cycle GFS forecasts. The FNL environmental winds show substantial VWS over the 48-h period beginning 1200 UTC 29 September that coincides with Joaquin's southwestward motion (Figs. 9a,b). Northeasterly environmental winds, associated with the height gradient between the upper-level ridge to the northwest and the upper-level trough to the southeast (Fig. 1a), intensify above $600 \mathrm{hPa}$. Joaquin's northeastward motion out of the Bahamas after 1200 UTC 2 October coincides with southwesterly environmental winds developing over the 850-500-hPa layer (Figs. 9c,d). This is consistent with anticyclonic deep-layer winds west of Joaquin becoming cyclonic as the digging eastern U.S. trough erodes the upper-level ridging northwest of Joaquin and lower-level ridging over Cuba (Fig. 1).

Compared to the $0.25^{\circ}$-FNL, the 1200 UTC 29 September GFS initialized environmental winds have a $1-2 \mathrm{~m} \mathrm{~s}^{-1}$ easterly wind speed bias below $400 \mathrm{hPa}$ and a $1-2 \mathrm{~m} \mathrm{~s}^{-1}$ southerly wind speed bias in the 550 750-hPa layer (Figs. 9a,b). Twelve hours later, the GFS southerly wind speed bias has increased to $\sim 2 \mathrm{~m} \mathrm{~s}^{-1}$ in a deep layer. This bias grows larger in the upper levels after $24 \mathrm{~h}$ (Fig. 9b), although by this time the environmental wind differences may be more strongly related to the GFS-forecast Joaquin moving into a different large-scale flow environment, given its substantial track divergence from observations (cf. Figs. 3 and $8 \mathrm{a}$ ). The 1200 UTC 30 September cycle GFS environmental winds show less difference from the $0.25^{\circ}$-FNL over the first 30 forecast hours, consistent with the smaller track errors over this period, but they have the same general easterly and southerly biases (Figs. 9c,d).

Figure 10 shows large-scale geopotential height differences between the 1200 UTC 30 September cycle GFS forecast and the $0.25^{\circ}$-FNL, averaged over the lower, middle, and upper portions of the $850-250-\mathrm{hPa}$ FNL optimal steering layer for two representative times. The 12-h GFS forecast turns Joaquin west while CTL and the observed storm continue moving southwest for another $24 \mathrm{~h}$ (cf. Figs. 3 and 8a). For the 850-650-hPa layer (Fig. 10a), the 12-h GFS forecast generates $5-10-\mathrm{m}$ lower heights around the base of the eastern U.S. trough and stronger low-level ridging northeast of the frontal wave centered near $27^{\circ} \mathrm{N}, 60^{\circ} \mathrm{W}$. The GFS-forecast mid- to upper-level environment similarly has a low (high) height bias west (northeast) of Joaquin (Figs. 10b,c) due to its stronger eastern U.S. trough, weaker downstream ridging northwest of Joaquin, and weaker mid- to upper-level low well northeast of the storm near $33^{\circ} \mathrm{N}, 55^{\circ} \mathrm{W}$. Twenty-four hours later, the 36 -h GFS forecast is turning Joaquin onto a long-term northward heading, eventually bringing it to a U.S. landfall, while the observed storm is located over $100 \mathrm{~km}$ farther south and slowly moving westward (cf. Figs. 3 and 8a). Compared to the 12-h forecast, the 36-h GFS forecast heights show similar, albeit more pronounced, differences from the $0.25^{\circ}$-FNL. The more strongly positive GFS zonal near-storm height anomaly gradient is consistent with the increased southerly GFS environmental wind anomaly through a deep layer (cf. Figs. 9d and 10d-f). The largest differences from the $0.25^{\circ}-\mathrm{FNL}$ are found above $650 \mathrm{hPa}$ over Florida and adjacent Atlantic waters, where the GFS-forecast eastern U.S. trough is deeper, and near $24^{\circ}-33^{\circ} \mathrm{N}, 55^{\circ} \mathrm{W}$ where the GFSforecast mid- to upper-level trough, along with its lower-level reflection, are weaker. N18 showed similar differences in 24-h forecast large-scale 700-hPa height patterns between their deterministic WRF simulation that captured the looping track and a composited 

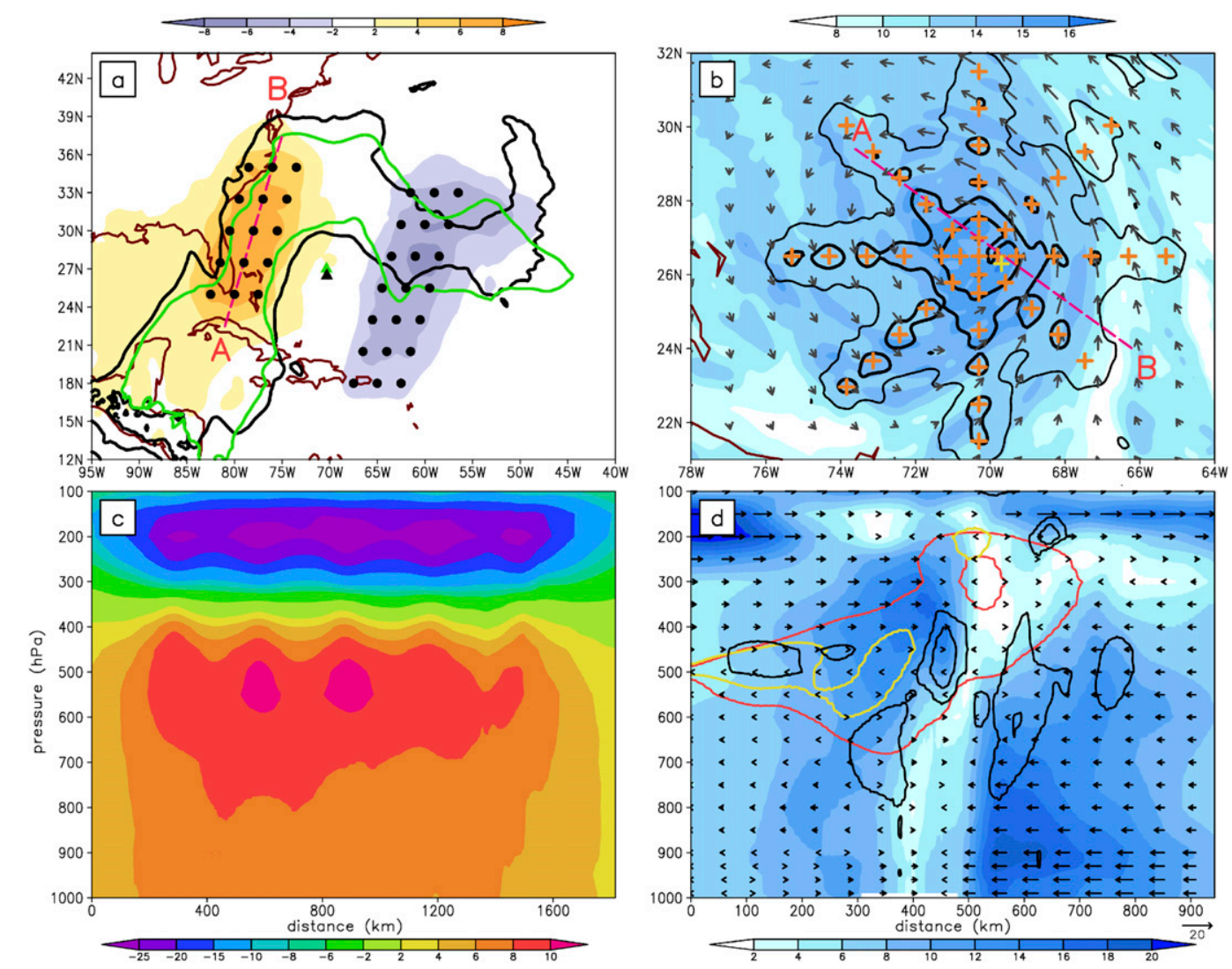

FIG. 13. Perturbed initial conditions used for WRF sensitivity tests. (a) Geopotential height differences (shaded, $\mathrm{m}$ ) between the PERT-R_WE and CTL analyses (PERT-R_WE - CTL), averaged over the 850-350-hPa layer. Green (black) contours show the CTL (0600 UTC 29 Sep 0.25-FNL) 5880-m 500-hPa geopotential height. Green (black) triangles mark the CTL surface (best track) storm center, while black dots mark the locations of synthetic 300-hPa temperature observations used in generating the PERT-R_WE analysis. (b) Differences in 850-hPa water vapor mixing ratio between the PERT-V and CTL analyses (PERT-V - CTL; $\mathrm{g} \mathrm{kg}^{-1} ;-1$, thin contours, and -3 and -5 , thick contours), with CTL analyzed 850 -hPa water vapor mixing ratio (shaded, $\mathrm{g} \mathrm{kg}^{-1}$ ) and horizontal winds (vectors, $\mathrm{m} \mathrm{s}^{-1}$ ). Orange (yellow) crosses mark synthetic moisture (temperature) sounding locations used in generating the PERT-V analysis. (c) Geopotential height differences (shaded, $\mathrm{m}$ ) between the PERT-R_WE and CTL analyses (PERT-R_WE - CTL), averaged along a 36-km-wide vertical cross section taken along the line running from $A$ to $B$ in (a). (d) Vertical cross section of the CTL analyzed horizontal wind speed (shaded, $\mathrm{m} \mathrm{s}^{-1}$ ), with analysis horizontal wind speed differences (PERT-V - CTL, -2 and $-4 \mathrm{~m} \mathrm{~s}^{-1}$, contoured in black), taken along a 36-km wide line running from A to B in (b). Red (yellow) contours denote CTL (PERT-V) temperature anomalies [ $T^{\prime}(z), 3,5 \mathrm{~K}$; calculated with respect to a $500-1500-\mathrm{km}$ annular averaged CTL reference profile]. Horizontal in-plane flow vectors for the CTL analysis are also shown.

group of U.S. landfalling ensemble members (see their Fig. 15f).

Next, we apply the GD13 TC motion error budget equation to both representative GFS forecasts to determine whether model misrepresentation of the vortex size or depth also contributes to the track forecast error (Fig. 11). As in GD13, we restrict this analysis to the first 24 -h forecast, so that the modeled and observed storm steering environments are not too far apart relative to the scale of the flow features being studied. For the forecast initialized on 29 September, the northwesterly directed environmental wind error and northeasterly directed vortex depth error vectors both contribute significantly toward a $\sim 2 \mathrm{~m} \mathrm{~s}^{-1}$ northerly TC motion error. The vortex depth error results from the shallower GFS 12-24-h forecast optimal steering layer, which extends up to $\sim 400 \mathrm{hPa}$ (Figs. 9a,b), compared to the 850-250-hPa $0.25^{\circ}$-FNL optimal steering layer for the period of Joaquin's southwest movement (not shown). This calculation implies that the GFS forecasts a shallower vortex that is less affected by northeasterly steering winds above 

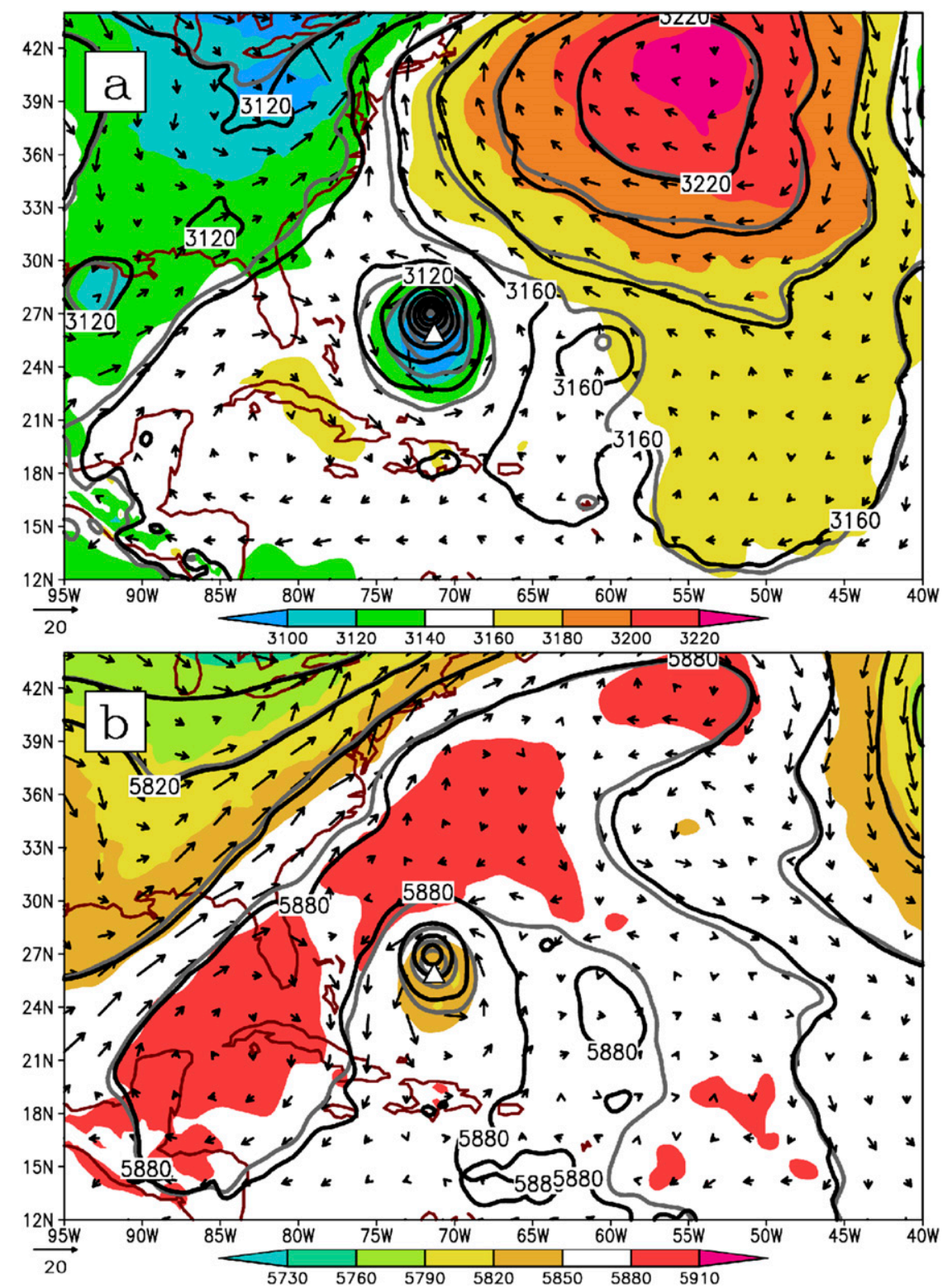

FIG. 14. (a) Geopotential height (shaded, $\mathrm{m}$ ) and horizontal flow vectors $\left(\mathrm{m} \mathrm{s}^{-1}\right)$ from the 0000 UTC 30 Sep NCEP $0.25^{\circ}$-FNL with NONUDGE 18 -h forecast geopotential height (m) contoured in black at 20-m intervals and PERT-R_WE 18-h forecast geopotential height contoured in gray over the same interval range, all from the 700-hPa level. (b) As in (a), but from the 500-hPa level, with NONUDGE and PERT-R_WE geopotential height contoured at 30-m intervals. White triangles denote the 0000 UTC 30 Sep best track Joaquin position.

$400 \mathrm{hPa}$ (Figs. 9a,b), as compared to the true storm. In contrast, the GFS forecast initialized on 30 September has a 12-24-h northerly motion error of $\sim 1 \mathrm{~m} \mathrm{~s}^{-1}$, which results primarily from the environmental wind error, as the steering layer is now deeper, extending up to $\sim 300 \mathrm{hPa}$ (cf. Figs. 9c,d and 11). Both the vortex removal radius error and residual remain relatively small for these GFS forecasts.

\section{b. Sensitivity tests to WRF initial conditions}

We now evaluate the relative impacts of the GFSdiagnosed environmental wind and vortex depth errors on Joaquin's motion by running WRF sensitivity simulations from perturbed analyses with nudging turned off while all other settings are kept identical to CTL. The first sensitivity test is termed as NONUDGE, 

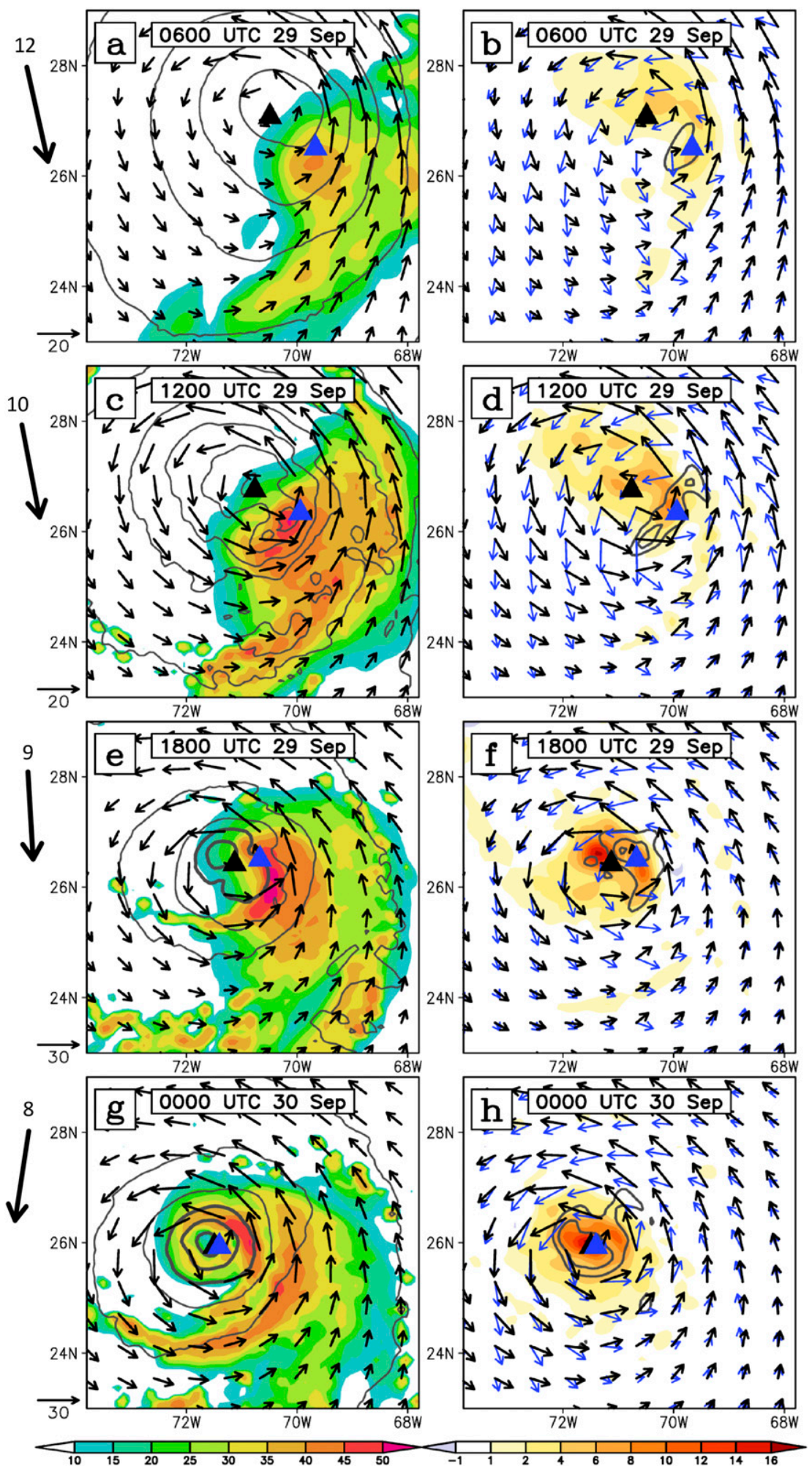

FIG. 15. (a) CTL analyzed composite reflectivity (dBZ, shaded) with sea level pressure (hPa; thick gray contours below $1000 \mathrm{hPa}$, thin gray contours for $1000 \mathrm{hPa}$ and above) and 850 -hPa horizontal winds $\left(\mathrm{m} \mathrm{s}^{-1}\right)$, valid at 0600 UTC 29 Sep. Thick black arrow to the left of the panel denotes the $850-200-\mathrm{hPa}$ VWS vector, with its magnitude $\left(\mathrm{m} \mathrm{s}^{-1}\right)$ labeled above. (b) As in (a), but for relative vorticity $\left(\times 10^{4} \mathrm{~s}^{-1}\right)$ at $850 \mathrm{hPa}$ 
in which nudging is turned off but the CTL analysis is not perturbed. Although NONUDGE also captures the looping track, with southwestward motion followed by a northeast turn (albeit in the wrong direction), it fails to generate sustained southward motion during the first $24 \mathrm{~h}$ (Fig. 8a). The track differences between CTL and NONUDGE may result from a combination of (i) model physics error in the outer three domains, and (ii) biases in the CTL initial conditions with respect to the $1^{\circ}$-FNL, shown in Fig. 12. In the lower levels, we find a CTL low-height bias over a broad region extending northward, southward and westward from Joaquin that encompasses much of the continental United States east of the Rockies, Gulf of Mexico, and Central America; particularly notable are the $>6 \mathrm{~m}$ lower CTL heights immediately northwest of Joaquin that extend from the Cuba ridge to the southwest corner of the North Atlantic ridge centered near $37^{\circ} \mathrm{N}$, $55^{\circ} \mathrm{W}$ (Fig. 12a). The central portion of the latter ridge is also stronger in CTL. In the mid- to upper levels (Fig. 12b), the subtropical ridge directly northwest of Joaquin and the upper-level trough centered near $37^{\circ} \mathrm{N}, 55^{\circ} \mathrm{W}$ are both weaker in CTL. Overall, the CTL initial conditions and GFS 12-h forecast valid $42 \mathrm{~h}$ later (Figs. 10a-c) share similar differences from the $0.25^{\circ}$-FNL in their representation of large-scale features surrounding Joaquin.

Using the CTL initial condition and GFS forecast biases as a starting point, we now identify features in Joaquin's environment that may be important to its steering. We perturb these features in the CTL analysis, one at a time, using the methods of section $3 \mathrm{~b}$ and rerun CTL without nudging (Table 1; Figs. 12 and 13). The first three tests are designed to strengthen the northerly geostrophic winds across Joaquin's near-storm environment. PERT-R_W enhances midto upper-level ridging immediately west of Joaquin, PERT-R_E weakens mid- to upper-level ridging immediately to the east, and PERT-R_WE combines the impacts of PERT-R_W and PERT-R_E. In PERT-R_WE for example, generating a 300-hPa cold anomaly along the axis of the ridge northwest of Joaquin increases heights by $\sim 4-10 \mathrm{~m}$ over a deep layer below, with the greatest impacts between 400 and $700 \mathrm{hPa}$ (Figs. 13a,c). The next two experiments test the sensitivity of Joaquin's southwest motion to perturbations in more distant features. PERT-R_ATL weakens the central portion of the northern Atlantic 700-hPa ridgehere the intention is to weaken the low-level anticyclonic flows on its southwestern periphery. PERT-T investigates whether weakening the eastern U.S. trough might strengthen (or at least delay the weakening of) the downstream subtropical ridge northwest of Joaquin. PERT-V tests the sensitivity of Joaquin's motion to a weakened vortex. Compared to CTL, the PERT-V analyzed upper-level warm temperature anomaly is weakened by $\sim 50 \%$ and $850-\mathrm{hPa}$ water vapor mixing ratios are reduced by $>3 \mathrm{~g} \mathrm{~kg}^{-1}$ inside of a $2^{\circ}$ latitude radius (Figs. 13b,d). The multivariate hybrid background error covariances have also slightly weakened and broadened the $800-400-\mathrm{hPa}$ layer vortex circulation (Fig. 13d).

Among all sensitivity experiments, PERT-R_WE yields the most significant increase in southward motion, with its forecast track falling roughly halfway in between those of NONUDGE and CTL over the first $48 \mathrm{~h}$ (Fig. 8a). The GD13 TC motion error budget confirms that the PERT-R_WE track forecast improvement results from a $\sim 70 \%$ smaller northerly directed environmental wind error (Fig. 11). The PERT-R_WE analysis perturbations persist after 18-h model integration, when ridging west (east) of Joaquin remains stronger (weaker) compared to NONUDGE at both 700 and $500 \mathrm{hPa}$ (Fig. 14). Notably, the 18-h PERT-R_WE forecast removes the anomalous NONUDGE ridging immediately east of Joaquin that is not present in the $0.25^{\circ}-\mathrm{FNL}$ (Figs. 14a,b). The PERT-R_W and PERT-R_E forecast tracks are similar and they fall roughly halfway between the NONUDGE and PERT-R_WE tracks (not shown). By contrast, PERT-R_ATL and PERT-T yield no track forecast improvement compared to NONUDGE (also not shown). While it is tempting to conclude, based on these results, that Joaquin's southwest motion is less sensitive to the North Atlantic 700-hPa ridge and eastern U.S. trough compared to the

\footnotetext{
$\longleftarrow$

(shaded) and at $500 \mathrm{hPa}$ (contoured for $4,8,12$ ). Black (blue) vectors show $850-\mathrm{hPa}$ $(500 \mathrm{hPa})$ horizontal winds $\left(\mathrm{m} \mathrm{s}^{-1}\right)$, scaled to the vector length from (a). Black (blue) triangles show the $850-\mathrm{hPa}(500 \mathrm{hPa})$ circulation center. (c), (d) As in (a),(b), but for the 6-h CTL forecast, valid at 1200 UTC 29 Sep. (e),(f) As in (a),(b), but for the 12-h CTL forecast, valid at 1800 UTC 29 Sep. (g),(h) As in (a),(b), but for the 18-h CTL forecast, valid at 0000 UTC $30 \mathrm{Sep}$. Sea level pressure is contoured at 2 -hPa intervals for (a),(c) and 4-hPa intervals for (e),(g). All variables are taken from the 9-km model domain.
} 


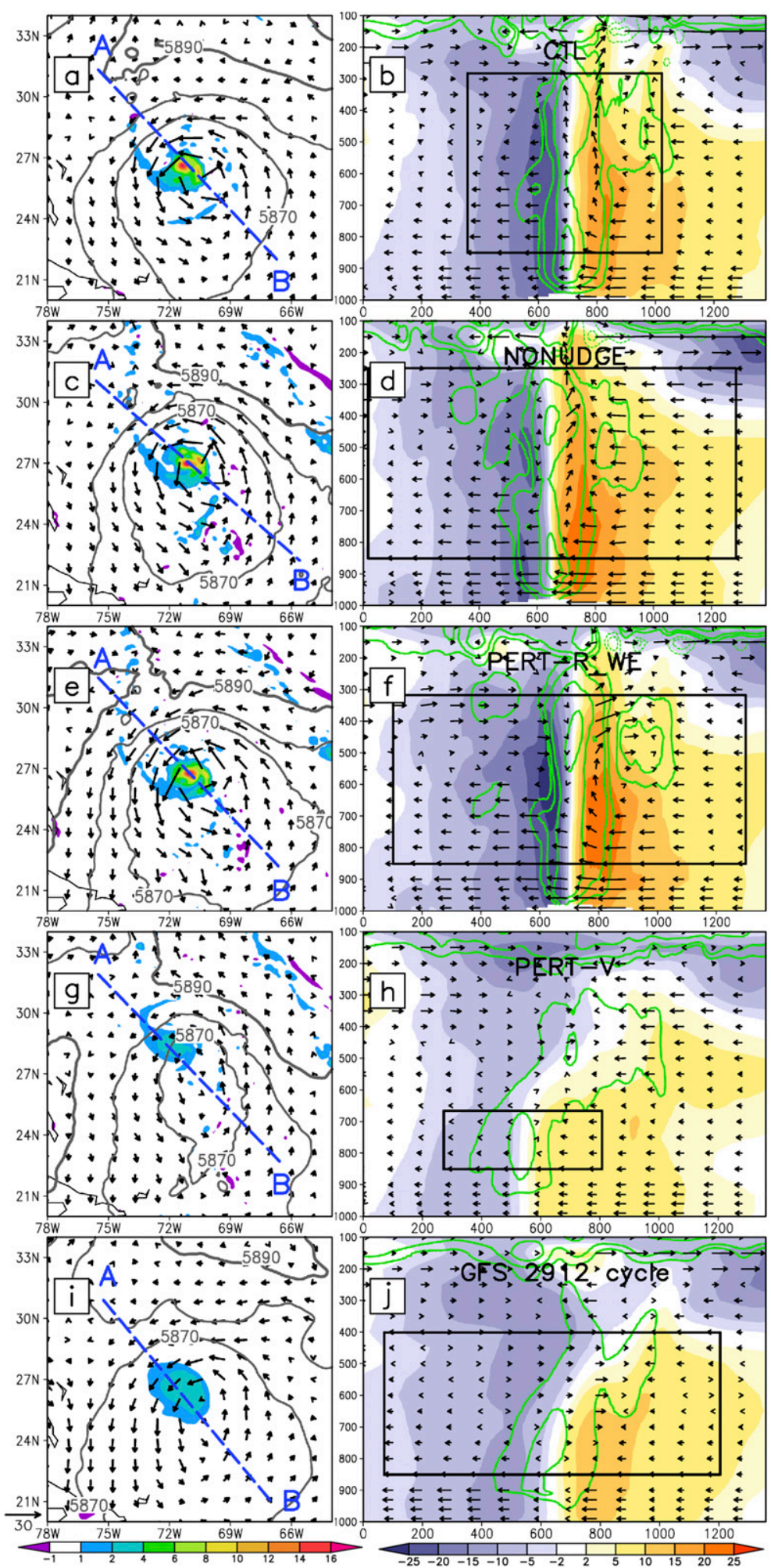

FIG. 16. (a) CTL 12 -h forecast $500-\mathrm{hPa}$ horizontal wind vectors $\left(\mathrm{m} \mathrm{s}^{-1}\right)$ with geopotential height (contoured every $10 \mathrm{~m}$ over the $5870-5890 \mathrm{~m}$ range), superimposed over 850 -hPa relative vorticity $\left(\times 10^{4} \mathrm{~s}^{-1}\right)$. (b) Vertical cross section, $90 \mathrm{~km}$ wide, taken along the line running from $A$ to $B$ in (a), with distances $(\mathrm{km})$ marked on the abscissa. Horizontal winds normal to the cross section are shaded $\left(\mathrm{m} \mathrm{s}^{-1}\right)$, 
near-storm environment, it is possible that a different experiment design that perturbed the former two features more strongly and/or from an earlier forecast start time could have elicited a stronger track response. Nevertheless, our results are consistent with N18 and Torn et al. (2018), who found that Joaquin's early southwest motion was more sensitive to the near-storm environment than to more distant synoptic-scale features. PERT-V, on the other hand, steers Joaquin's lower-level center due northwest (Fig. 8a). It also fails to intensify the storm (Figs. 8b,c) and align the lowerlevel and upper-level centers (not shown). The GD13 error budget analysis confirms that the largest contributor to the $\sim 4 \mathrm{~m} \mathrm{~s}^{-1}$ PERT-V northward motion error is the vortex depth error, which had been near zero for NONUDGE (Fig. 11).

\section{c. Impact of vortex structural changes on Joaquin's motion}

It is possible that changes to Joaquin's vortex structure may have also helped draw the center southward during the early CTL simulation period (i.e., prior to 0000 UTC 30 September). That is, Joaquin's vortex undergoes the following two simultaneous processes that have been well documented in observational, modeling and theoretical studies of TCs intensifying under moderate VWS (Reasor et al. 2013; Rogers et al. 2015; Nguyen and Molinari 2015; Rios-Berrios et al. 2016, 2018): (i) axisymmetrization, as convection that had previously been focused south of the center wraps into the upshear quadrants (Figs. 5a-d), and (ii) reduction in the vertical tilt (Fig. 8a). For some moderately sheared TCs, particularly those in early stages of development, these two processes may be driven by downshear vortex reformation. As an example, explosive deep convection on the downshear (eastern) side of Tropical Storm Gabrielle (2001) facilitated the concentration of low-level cyclonic vorticity through convergence and stretching; the new vortex grew vertically deep while absorbing the parent circulation over a 4-h period prior to landfall in southwest Florida (Nguyen and Molinari 2015). This process likely accounted for Gabrielle having a best track speed that was nearly double the mean environmental flow speed over this period (Molinari et al. 2006).

Figure 15 shows the evolution of the CTL radar reflectivity, sea level pressure (SLP) field, and 850- and 500 -hPa level circulations over the first $18 \mathrm{~h}$. At the CTL initial time, the vortex tilts downshear-left and deep convection is confined to the downshear quadrants (Figs. 15a,b). Six hours later, a local SLP minimum has developed where the downshear-left corner of a larger, elliptically shaped low-level circulation intersects the northwest edge of the deep convection (Fig. 15c). The local SLP minimum is collocated with enhanced low-level cyclonic vorticity, and it lies beneath the upper-level center (Fig. 15d). By 1800 UTC 29 September, deep convection has wrapped cyclonically into the upshear-left quadrant and the low-level circulation has contracted and intensified (Fig. 15e). While both the upper-level and lower-level centers have continued moving southwestward (Fig. 8a), the former is now positioned upshear-left relative to the latter, and the tilt is reduced to $\sim 30 \mathrm{~km}$, compared to $\sim 80 \mathrm{~km}$ 6-h prior (Figs. 15d,f). Six hours later the vortex is vertically aligned and a closed circular eyewall has formed (Figs. 15g,h). The CTL vortex structural changes over the 0600 UTC 29-0000 UTC 30 September period bear some similarity to the Tropical Strom Gabrielle downshear reformation process [see Figs. 7, 9, and 15 in Nguyen and Molinari (2015)]; however, unlike for Gabrielle, the developing downshear circulation in Joaquin never fully "takes over" from the parent circulation. Rather, both centers merge in concert with the vortex vertical alignment (Figs. 15b,d,f). A deeper investigation of the dynamical and thermodynamic processes driving these structural changes, and how they relate to Joaquin's RI, warrants a further study.

To what extent did the contraction and vertical alignment of Joaquin's vortex cause additional southward motion in the low-level center that cannot be accounted for by the environmental winds? Between 0600 and 1800 UTC 29 September, the CTL 850-hPa

\footnotetext{
with positive (negative) values assigned to winds directed into (out of) the page. Green contours plot Ertel potential vorticity $(-2,-1,1,2,4,8,12$ PVU, dotted for negative values, $\left.1 \mathrm{PVU}=10^{-6} \mathrm{~K} \mathrm{~kg}^{-1} \mathrm{~m}^{2} \mathrm{~s}^{-1}\right)$. In-plane flow vectors $\left(\mathrm{m} \mathrm{s}^{-1}\right.$; vertical motions multiplied by 5) are also shown. Black rectangles show the optimal steering flow volume centered on the low-level storm center, with dimensions averaged over the 6-18-h period. (c)-(j) As in (a),(b), but for the 12-h NONUDGE, PERT-R_WE, PERT-V, and 1200 UTC 29 Sep cycle GFS forecasts. For (b),(d),(f),(h),(j) flow vectors are scaled to $20 \mathrm{~m} \mathrm{~s}^{-1}$ for the same unit vector length used for (a),(c),(e),(g),(i).
} 
center moves southwest with motion vector $\left(c_{X}, c_{Y}\right)=$ $(-1.46,-1.67) \mathrm{m} \mathrm{s}^{-1}$. Applying the optimal steering flow calculation (see section 3c) to CTL at 1200 UTC 29 September yields the vertically averaged environmental wind vector $\left(U_{\text {opt }}, V_{\text {opt }}\right)=(-1.86,-0.87) \mathrm{m} \mathrm{s}^{-1}$, with a steering depth and vortex removal radius of $850-250 \mathrm{hPa}$ and $700 \mathrm{~km}$, respectively. Despite being a rough estimate, ${ }^{2}$ this calculation implies that vortex reorganization over the first $12 \mathrm{~h}$ causes a $0.4 \mathrm{~m} \mathrm{~s}^{-1}$ eastward and $0.8 \mathrm{~m} \mathrm{~s}^{-1}$ southward deviation from the environmental steering winds in the CTL motion-a significant contribution.

\section{d. Vortex-scale response to steering environment}

The steering flow analysis in sections $5 \mathrm{a}-\mathrm{c}$ above has explored the sensitivity of Joaquin's motion to environmental steering features, vortex intensity and depth, and vortex reformation. In reality, TC steering is controlled by the interaction between the cyclonic circulation and the environmental flow. Let us now take a closer look at how Joaquin's circulation interacts with the steering environment using vertical cross sections taken through five representative 12-h forecasts. All cross sections are taken in the NW-SE direction, which is approximately orthogonal to Joaquin's observed motion during these times.

The 12-h CTL vortex, now near-vertically aligned, has a notable circulation asymmetry, with stronger (weaker) northeasterly (southwesterly) winds northwest (southeast) of the center. This pattern is evident both in the 500-hPa planar view (Fig. 16a) and in winds orthogonal to the cross section inside of the $\sim 333-\mathrm{km}$ optimal steering radius, especially above $600 \mathrm{hPa}$ (Fig. 16b). Removal of the azimuthally averaged tangential winds would yield residual northeasterly winds in the northwestern circulation that may be important in steering Joaquin southwestward. In contrast, the westward-moving NONUDGE storm (Fig. 8a) circulation is more symmetric through a deep layer (Figs. 16c,d). Nudging wind and temperature on the 3 fixed domains toward the $1^{\circ}$-FNL has realigned the strongest $500-\mathrm{hPa}$ ridging, denoted by the 5890-m contour, from northeast of the center in NONUDGE to due north of the center in CTL (Figs. 16a-d). PERT-R_WE, which has partially recovered the observed southwest motion (Fig. 8a), shows a near-storm 500-hPa environment more like CTL, with enhanced ridging north and west

\footnotetext{
${ }^{2}$ This calculation assumes that the environmental steering winds, vortex depth, and vortex size at 1200 UTC 29 Sep remain constant over the \pm 6 -h window surrounding this time.
}

of the center (Fig. 16e). Compared to NONUDGE, PERT-R_WE has restored the northwest-southeast inner-core circulation asymmetry found in CTL, especially over the 700-400-hPa layer, where height perturbations in the initial conditions are largest (cf. Figs. $13 \mathrm{c}$ and $16 \mathrm{e}, \mathrm{f})$. Compared to the other three simulations, the PERT-V and 1200 UTC 29 September GFS 12-h forecasts both have considerably weaker vortices that tilt southeastward with height, and their highest cyclonic potential vorticity is concentrated below $650 \mathrm{hPa}$ (Figs. 16g-j), which is consistent with their significantly larger vortex depth errors (Fig. 11).

Returning to CTL and examining a few later times during its southwest movement period, we find that the strongest $500-\mathrm{hPa}$ ridging remains northwest of the storm, consistent with the $500-\mathrm{hPa}$ circulation being stronger on the northwest side and weaker on the southeast side of the center (Figs. 17a,c,e). Vertical cross sections show this circulation asymmetry to be prominent above $600 \mathrm{hPa}$ (Figs. 17b,d,f). These results suggest that Joaquin interacted with its steering environment over a broad radial band that extended deep into the inner-core region, to $<100 \mathrm{~km}$ from the storm center. Other high-resolution case studies (Marks et al. 1992; Liu et al. 1999) similarly found that TC steering could be largely explained by translational flows within the inner-core region.

\section{Summary and conclusions}

This study has examined the atmospheric features that steered Hurricane Joaquin (2015) onto its climatologically unusual looping track, where the storm tracked southwestward for several days followed by slow clockwise turning and recurvature to the northeast. We focused on the period of Joaquin's southwest motion, because (i) many early cycle operational forecasts struggled to capture the persistence of this motion, and (ii) this steering positioned the storm far enough south relative to a southeast U.S. mid- to upper-level low such that it could be steered out to sea rather than be pulled toward the U.S. coast by the winds surrounding the low.

We began by validating the $1-\mathrm{km}$ resolution WRF CTL simulation against observations. CTL initialized Joaquin as a weak tropical storm and reproduced its RI and looping track. The WRFDA-hybrid generated CTL initial conditions were biased relative to the $0.25^{\circ}$-FNL, whereby deep-layer ridging was too weak northwest of Joaquin; nudging of horizontal winds (temperature) toward the $1^{\circ}$-FNL on the outer three (two) domains adjusted the WRF large-scale conditions 


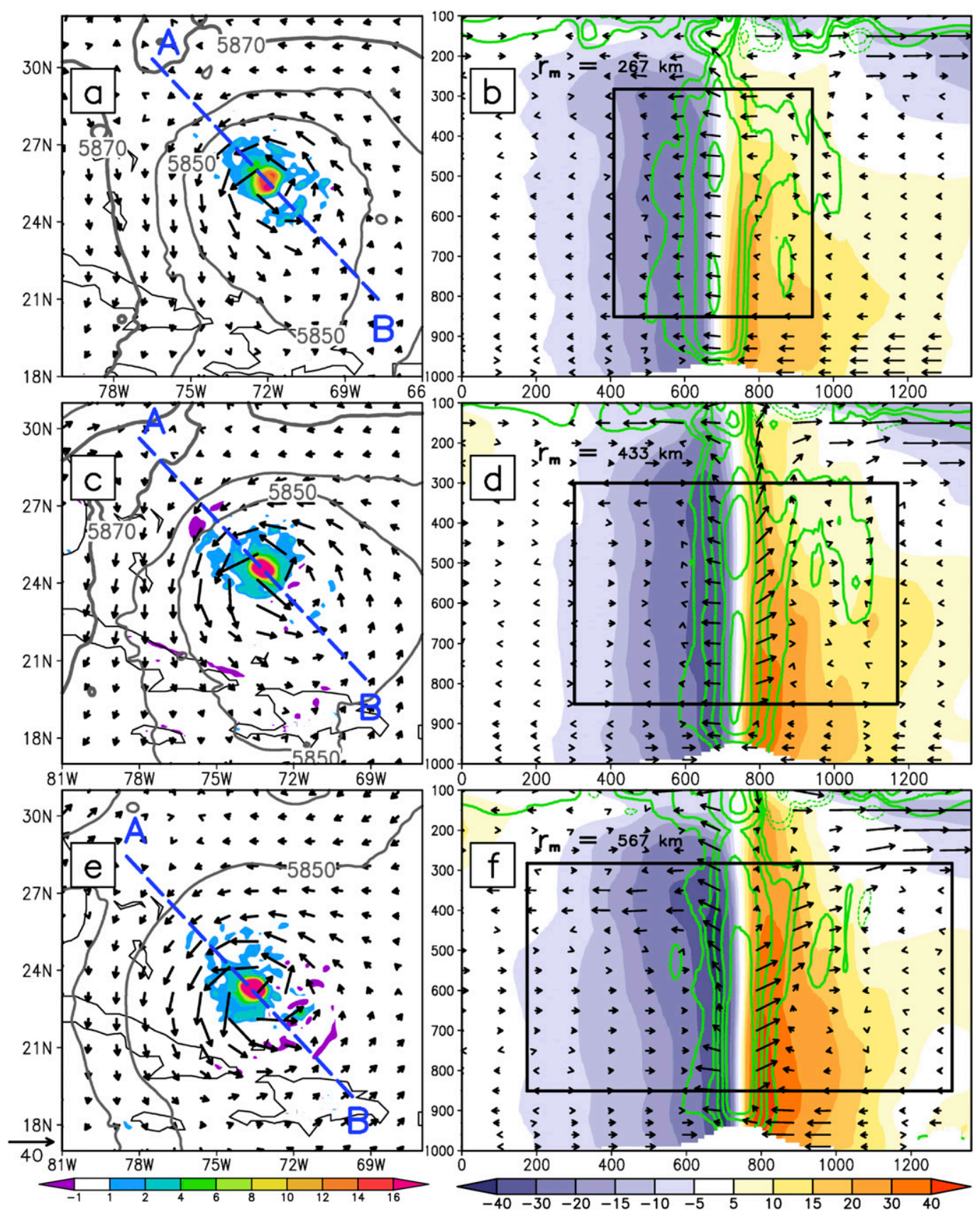

FIG. 17. As in Fig. 16, but for the (a),(b) CTL 24-h forecast, (c),(d) 36-h forecast, and (e),(f) 48-h forecast. For (a),(c),(e), the 5850, 5860, and $5870 \mathrm{~m} 500$-hPa geopotential height contours are shown. Note the different vector length scale used for (a),(c),(e) compared to Figs. 16a, 16c, 16e, 16g, and 16i. This length scales to $20 \mathrm{~m} \mathrm{~s}^{-1}$ for (b),(d),(f). Also note the different shading scale used for (b),(d),(f), compared to Figs. 16b, 16d, $16 \mathrm{f}, 16 \mathrm{~h}$, and $16 \mathrm{j}$.

such that by $24 \mathrm{~h}$ they were quite similar to those of the $0.25^{\circ}$-FNL (not shown).

Next, we analyzed steering flows for two representative operational GFS forecasts. Using the GD13 TC motion error budget equation, we found that the 1200 UTC 29 September cycle forecast failed to generate any sustained southward motion due to (i) a deep-layer southerly wind bias in the storm steering environment that was present in the initial conditions and grew larger over time and (ii) an insufficiently deep vortex that did not strongly interact with northeasterly environmental steering flows above $400 \mathrm{hPa}$. 
The 1200 UTC 30 September cycle GFS forecast, on the other hand, initialized a stronger, vertically aligned vortex that responded to a deeper steering layer. Here, northerly directed motion errors after $12 \mathrm{~h}$ resulted primarily from a deep-layer southerly environmental wind forecast bias relative to the $0.25^{\circ}$-FNL, which was shown to be consistent with inadequately strong ridging west of the storm at $12 \mathrm{~h}$, and with the GFS digging the eastern U.S. trough farther south and east over Florida at $36 \mathrm{~h}$. Berg (2016) compared 72-h GFS and ECMWF forecasts and similarly found a deeper vortex and a less progressive eastern U.S. trough in the ECMWF forecast, which had significantly lower track errors (see his Fig. 10).

A unique contribution from this study was to show, using WRF initial condition sensitivity tests, that Joaquin's southwest motion was sensitive to both track error sources diagnosed from the early cycle GFS forecasts: namely, the environmental wind and vortex depth errors. To simulate Joaquin's southwest motion, the WRF Model must generate both a sufficiently strong mid- to upper-level ridge northwest of the storm and a sufficiently deep vortex to interact with the geostrophic flows around the east side of the ridge. Cross sections taken from CTL during Joaquin's southwest-moving period show stronger mid- to upper-level winds northwest of the center, relative to the southeastern quadrant, which is consistent with the strongest nearby mid- to upperlevel ridging being located northwest of the vortex center. These findings are consistent with N18 and Torn et al. (2018), who similarly found that Joaquin's early southwest motion was most sensitive to small geopotential height and wind changes in the nearstorm environment and less sensitive to more distant features, such as the eastern U.S. trough. Like N18, we also find that Joaquin's motion after 0000 UTC 2 October may have become sensitive to the position of the eastern U.S. trough as it was evolving into a closed low, through comparison of the 1200 UTC 30 September cycle GFS forecast and FNL fields.

Unlike N18, however, we found that Joaquin's southwest motion could also be dependent on the vortex having sufficient depth. In part, these differences may stem from N18 finding the environmental flow uncertainty to be maximized in the lower troposphere, near $700 \mathrm{hPa}$, which should affect the motion of both deep and shallow TCs. However, we found vortex depth to be an important factor only for the "extreme case" forecasts that initialized Joaquin as a weak tropical storm and failed to intensify itnamely, the 1200 UTC 29 September cycle GFS and the PERT-V sensitivity test. GD13 similarly found insufficient vortex depth to be a significant contributor to Advanced Hurricane WRF (AHW) track errors during the early development of Hurricane Earl (2010). Our findings suggest that model misrepresentation of vortex depth may be an important track error source for some TC cases, especially for weaker, developing storms that are embedded in vertically sheared environmental flows. We also showed how Joaquin's vortex contraction and tilt reduction over the 0600 UTC 29 September-0000 UTC 30 September period may have helped to draw the low-level center southward.

Despite marked improvements in TC track forecasting over the past few decades, operational model forecasts can still contain large track errors, particularly for climatologically unusual cases (Zhang et al. 2018). Assimilating additional data over ocean regions, to include both satellite radiances and aircraft dropsondes sampling the synoptic environment, together with improved model physics, may lead to better model representation of large-scale flow features (Brennan and Majumdar 2011; GD13; Bassill 2015; Torn et al. 2015, 2018). Our results further suggest that for TCs developing in vertically sheared environments, improved inner-core sampling by means of cloudy radiances and aircraft reconnaissance missions may reduce track forecast errors by improving the model estimate of vortex depth in the initial conditions. Given that vortex depth is generally correlated with intensity, improvements in track forecasting may be partly contingent on more accurate intensity forecasts for these cases.

Acknowledgments. This work was funded by the U.S. Office of Naval Research Grants N000141410143, and N000141712210. We thank Chris Velden for providing us with the UW-CIMSS enhanced AMV observations that we assimilated in the WRFDA-hybrid and WRF-DART spinup cycles. We also thank Jeff Anderson, Glen Romine, Nancy Collins, Tim Hoar, and the rest of the DART project team for their kind assistance to William Miller while he was learning to use their software. The authors acknowledge the University of Maryland supercomputing resources (http:// hpcc.umd.edu) made available for conducting the research reported in this paper.

\section{APPENDIX}

\section{Data Assimilation Methodology}

\section{a. Cycling strategy}

A 30-h WRF spinup cycle, herein the WRFDAhybrid cycle, assimilates observations every $3 \mathrm{~h}$ using 


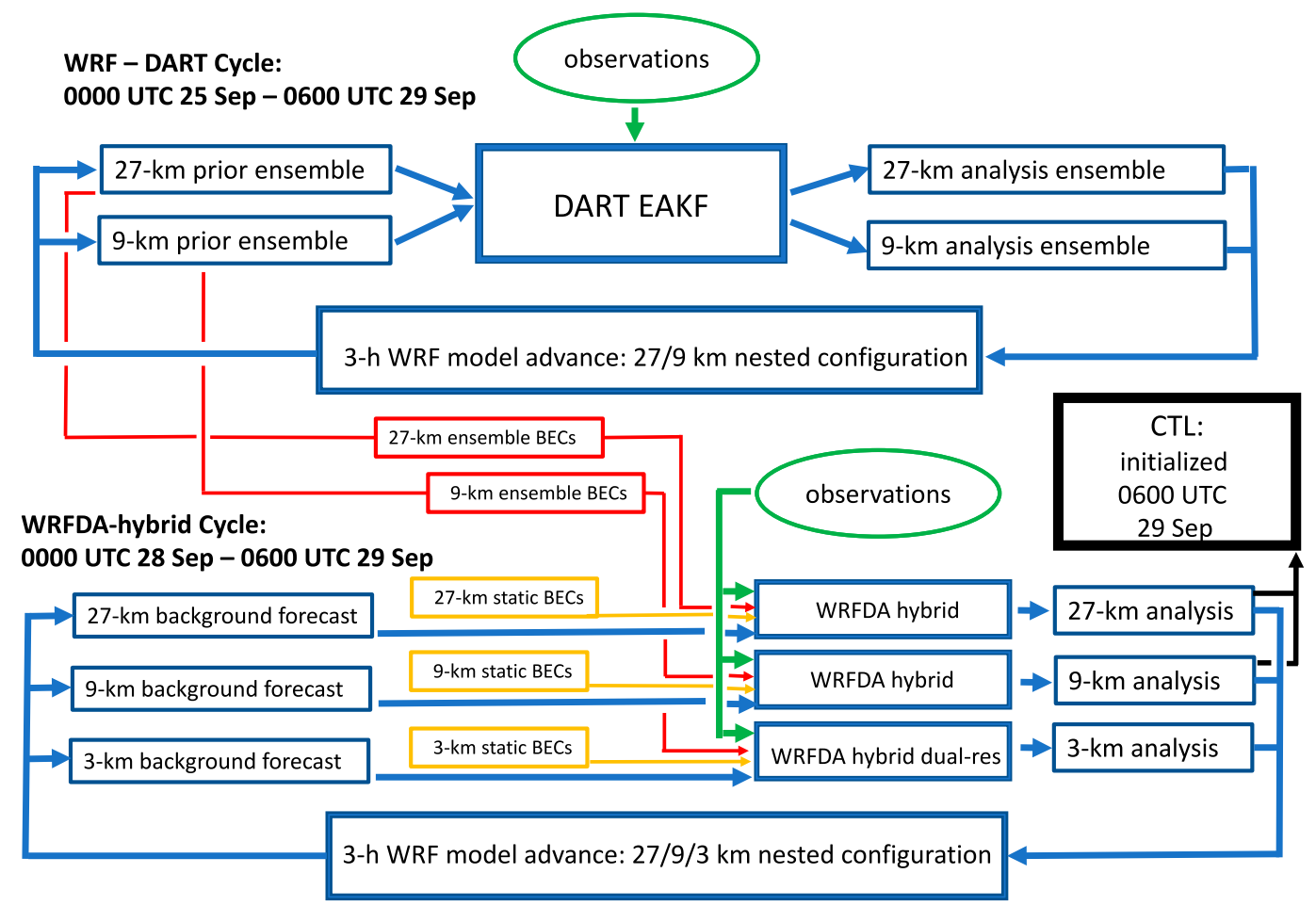

FIG. A1. Schematic summarizing the cycled data assimilation methodology used for generating the CTL analysis.

WRF Data Assimilation (WRFDA) V3.9 hybrid 3DVAR software (Wang et al. 2008a,b) with the purpose of generating accurate and dynamically balanced initial conditions for CTL (Fig. A1). WRF is run at 27/9/3-km resolution with the CTL 2-way nesting configuration (Fig. 2) and physics schemes, except that the Davis et al. (2008) SST parameterization is turned off. The WRFDA-hybrid cycle begins with a 3-h WRF forecast initialized from the 0000 UTC 28 September $1^{\circ}$-FNL, which becomes the background for the first hybrid analysis. The cycle continues, with hybrid analyses initializing 3-h WRF simulations. Data assimilation is performed separately on the 27 and $9-\mathrm{km}$ domains. The 3-km nest is interpolated from the 9-km analyses, except for 1800 and 2100 UTC 28 September, when inner-core reconnaissance flight data are available, and data assimilation is performed on the $3-\mathrm{km}$ background. To filter out noisy and potentially unbalanced features from the analyses, digital filter initialization (DFI, Lynch and Huang 1992) with a twice-DFI scheme and a Dolph Filter (Lynch 1997) is applied at the beginning of all cycled WRF runs, using 2-h backward and forward integrations. The DFI-processed 0600 UTC 29 September analysis is used to initialize CTL.

An 80-member 27/9-km WRF forecast ensemble, herein the WRF-DART cycle (Fig. A1), provides ensemble-based "errors of the day" to the hybrid 3DVAR algorithm. The ensemble initial conditions are seeded at 0000 UTC 25 September by adding random Gaussian draws taken from the 27-km domain static "CV5" background error field to the $1^{\circ}$-FNL (Torn et al. 2006). Lateral boundary conditions for the 27-km domain are perturbed similarly. Following an initial 6-h WRF ensemble forecast, ${ }^{\mathrm{A} 1}$ observations are assimilated every $3 \mathrm{~h}$ using the Data Assimilation Research Testbed (DART) ensemble adjustment Kalman filter (EAKF, Anderson 2001, 2009). The WRF-DART cycle is initialized 3 days prior to the first hybrid analysis so that the system has sufficient time to develop spread representative of the flowdependent errors.

\section{b. Data assimilation algorithms}

Wang et al. (2008a) describe the WRFDA hybrid 3DVAR algorithm in detail. Here, equal weighting between the static and ensemble background error covariances (BECs) is used, and the horizontal length scale of the recursive filter used to localize the

\footnotetext{
${ }^{\mathrm{A} 1}$ Except for the omission of the 3-km nest, WRF Model settings are the same as those for the WRFDA-hybrid cycle. DFI is also not used for WRF-DART model advances.
} 
TABLE A1. Observations assimilated into the WRFDA-hybrid and WRF-DART cycles.

\begin{tabular}{|c|c|c|c|c|}
\hline Platform & $\begin{array}{l}\text { Observation } \\
\text { type }\end{array}$ & $\begin{array}{l}\text { Assimilated } \\
\text { in DART } \\
\text { EAKF }\end{array}$ & $\begin{array}{l}\text { Assimilated in } \\
\text { WRFDA-hybrid }\end{array}$ & Notes \\
\hline Radiosondes & $u, v, T, q$ & Yes & Yes & $\begin{array}{l}q \text { assimilated as relative humidity in WRFDA-hybrid, } \\
\text { specific humidity in DART EAKF }\end{array}$ \\
\hline Satellite AMVs & $u, v$ & Yes & Yes & $\begin{array}{l}\text { Superobbed into } 81 \mathrm{~km} \times 81 \mathrm{~km} \times 25 \mathrm{hPa} \text { boxes; } \\
\text { taken from UW-CIMSS and NOAA/NESDIS }\end{array}$ \\
\hline Aircraft & $u, v, T$ & Yes & Yes & Superobbed into $81 \mathrm{~km} \times 81 \mathrm{~km} \times 25 \mathrm{hPa}$ boxes \\
\hline $\begin{array}{l}\text { U.S. Air Force C-130 recon } \\
\text { flight-level data }\end{array}$ & $u, v, T$ & Yes & Yes & $\begin{array}{l}1800 \text { and } 2100 \text { UTC } 28 \text { Sep analyses only; for } \\
\text { DART EAKF, thinned to 18-km along-track } \\
\text { intervals, for WRFDA hybrid, thinned to 6-km } \\
\text { along-track intervals }\end{array}$ \\
\hline AMSU-A & Radiance & No & Yes & $\begin{array}{l}\text { Thinned to } 108,36 \text {, and } 18-\mathrm{km} \text { mesh for WRF } \\
\text { domains } 1,2 \text {, and } 3 \text {, respectively }\end{array}$ \\
\hline Bogus & $q$ & No & Yes & $\begin{array}{l}\text { Assimilated as relative humidity over the } \\
1000-700-\mathrm{hPa} \text { layer in } 50-\mathrm{hPa} \text { intervals, in } \\
\text { concentric arcs } S \text { of storm center }\end{array}$ \\
\hline NHC Advisory lat, lon, $P_{\mathrm{MIN}}$ & - & Yes & No & $\begin{array}{l}\text { Data are linearly interpolated in time to } 3-\mathrm{h} \\
\text { analyses between } 6-\mathrm{h} \text { advisories }\end{array}$ \\
\hline
\end{tabular}

ensemble BECs in model space is set to $750 \mathrm{~km}$, which corresponds to an $e$-folding distance of $\sim 2100 \mathrm{~km}$. Two "outer loops" are used to minimize the cost function (Schwartz et al. 2013). When assimilating observations into the $3-\mathrm{km}$ domain, ensemble perturbations are interpolated from the 9-km WRFDART forecast using the WRFDA hybrid "dual resolution" algorithm (Schwartz et al. 2015). The "NMC method" (Parrish and Derber 1992) is used to generate the static BECs (CV5 option) from differences in 12 and 24-h WRF forecasts verifying at the same time, gathered over a 40-day period prior to the start of the WRFDAhybrid cycle.

The DART EAKF ingests observations with the purpose of adjusting the analysis ensemble mean toward the truth while maintaining a spread representative of the flow-dependent errors. For brevity, we mention only key settings, which follow previous successful studies (Torn 2010; Cavallo et al. 2013; Wu et al. 2014, 2015). To compensate for spread deficiency, which can result from a finite-sized ensemble not capturing model error and other sources of uncertainty, inflation, with an initial standard deviation of 0.6 , is applied to the background ensembles prior to assimilation and allowed to vary in time and space (Anderson 2009). Densely observed regions evolve higher inflation values. To prevent unnecessarily high inflation for later periods, should the local observation density decrease, the inflation fields are damped by $10 \%$ every cycle. Horizontal and vertical localization is applied, which limits the spatial influence that observations have on the model state, thereby mitigating analysis degradations caused by distant spurious correlations. We use a bell-shaped polynomial correlation function (Gaspari and Cohn 1999) that reaches zero $1910 \mathrm{~km}$ in the horizontal and $10 \mathrm{~km}$ in the vertical around each observation. The size of this ellipsoid is reduced if necessary by adaptive localization (Torn 2010) to limit the number of observations contained within it to approximately 1600 .

\section{c. Observations}

Table A1 summarizes the observations assimilated into the WRF-DART and WRFDA-hybrid cycles. They are assumed valid at the analysis times and taken from \pm 1.5 -h time windows, except for the C-130 flight-level winds and temperature, which are taken from \pm 30 -min windows. Conventional observations include radiosondes, atmospheric motion vectors (AMVs), and aircraft reports. The AMV winds are derived by tracking moving cloud and water vapor features in geostationary satellite imagery. The University of WisconsinMadison Cooperative Institute for Meteorological Satellite Studies (UW-CIMSS) AMVs are a high spatial resolution hourly dataset, available for the period beginning at 0000 UTC 28 September, whereas the NOAA/NESDIS AMVs are processed for global analyses and have a coarser resolution. Velden et al. (2017) describe the quality control algorithms used in processing the UW-CIMSS AMVs, which include the removal of all AMVs in the 400-700-hPa layer, where the vector height assignments have been found to be less accurate. To minimize spatial correlations in observation errors that are not accounted for in the data assimilation, all AMVs are averaged, or "superobbed," over 81-km wide and 25-hPa deep boxes. The "obserr.txt" table 
supplied with the WRFDA V3.9.1 software provides most observation errors. AMV errors are taken from Velden et al. (2017). C-130 flight-level wind and temperature errors are set to $2 \mathrm{~m} \mathrm{~s}^{-1}$ and $0.5 \mathrm{~K}$, respectively, following Aksoy et al. (2013). National Hurricane Center (NHC) advisory position and $P_{\min }$ errors are set to $0.2^{\circ}$ and $3 \mathrm{hPa}$, respectively.

The WRFDA-hybrid cycle assimilates Advanced Microwave Sounding Unit-A (AMSU-A) radiances from the NOAA-15, NOAA-18, NOAA-19, and MetOp-2 satellites. Only the temperature-sensitive channels 5, 6, and 7 are assimilated. These channels are not sensitive to surface emissivity and do not sample regions above the model top. The WRFDA Variational Bias Correction (VARBC) routines are used to correct for biases in the quality-controlled radiances; they add a correction term to the radiance forward operator consisting of a constant "offset" added to a linear combination of seven channeldependent predictors, which are related to field variables and the scan geometry, all multiplied by coefficients. The predictor coefficients are updated every cycle as part of the cost function minimization. To spin up the coefficients, WRFDA is run for a 40-day period prior to 0000 UTC 28 September in an "offline mode," following Liu et al. (2012), with the NCEP $1^{\circ}$-FNL used as the reference field.

Except for flight-level wind and temperature observations from one C-130 mission, inner-core observations are not available prior to the CTL initialization time. Previous studies have used bogus moisture soundings to enhance the background relative humidity near a developing TC (Hsiao et al. 2010; Schwartz et al. 2013, 2015). Microwave satellite observations (not shown) indicate that deep convection is displaced south of the surface low center during the WRFDA-hybrid cycling period. To help focus simulated convection in that region, bogus moisture soundings are seeded in concentric semicircles south of the NHC best track center extending out to $6^{\circ}$ of latitude. Figure 13 shows the same sounding configuration, except over a full $360^{\circ}$ circle. Each sounding increases relative humidity in the $1000-700-\mathrm{hPa}$ layer by a factor of $1.1^{\mathrm{A} 2}$ above the background.

\section{REFERENCES}

Aberson, S. D., 2010: 10 years of hurricane synoptic surveillance (1997-2006). Mon. Wea. Rev., 138, 1536-1549, https://doi.org/ 10.1175/2009MWR3090.1.

Aksoy, A., S. D. Aberson, T. Vukicevic, K. J. Sellwood, S. Lorsolo, and X. Zhang, 2013: Assimilation of high-resolution tropical

\footnotetext{
${ }^{\mathrm{A} 2}$ Larger factors were tested and found to overintensify the storm during the WRFDA-hybrid Cycle.
}

cyclone observations with an ensemble Kalman filter using NOAA/AOML/HRD's HEDAS: Evaluation of the 2008-11 vortex scale analyses. Mon. Wea. Rev., 141, 1842-1865, https:// doi.org/10.1175/MWR-D-12-00194.1.

Anderson, J. L., 2001: An ensemble adjustment Kalman filter for data assimilation. Mon. Wea. Rev., 129, 2884-2903, https:// doi.org/10.1175/1520-0493(2001)129<2884:AEAKFF>2.0.CO;2.

, 2009: Spatially and temporally varying adaptive covariance inflation for ensemble filters. Tellus, 61A, 72-83, https:// doi.org/10.1111/j.1600-0870.2008.00361.x.

Bassill, N. P., 2015: An analysis of the operational GFS simplified Arakawa-Schubert parameterization within a WRF framework: A Hurricane Sandy (2012) long-term track forecast perspective. J. Geophys. Res. Atmos., 120, 379-398, https:// doi.org/10.1002/2014JD022211.

Bentley, A. M., L. F. Bosart, and D. Keyser, 2017: Uppertropospheric precursors to the formation of subtropical cyclones that undergo tropical transition in the North Atlantic basin. Mon. Wea. Rev., 145, 503-520, https://doi.org/10.1175/ MWR-D-16-0263.1.

Berg, R., 2016: National Hurricane Center tropical cyclone report: Hurricane Joaquin (28 September-7 October 2015). Tech. Rep. AL112015, National Hurricane Center, 36 pp., https:// www.nhc.noaa.gov/data/tcr/AL112015_Joaquin.pdf.

Brennan, M. J., and S. J. Majumdar, 2011: An examination of model track forecast errors for Hurricane Ike (2008) in the Gulf of Mexico. Wea. Forecasting, 26, 848-867, https://doi.org/ 10.1175/WAF-D-10-05053.1.

Cangialosi, J., 2015: National Hurricane Center tropical cyclone report: Tropical Storm Ida (18-27 September 2015).Tech. Rep. AL102015, National Hurricane Center, 14 pp., https:// www.nhc.noaa.gov/data/tcr/AL102015_Ida.pdf.

__ , and J. Franklin, 2016: National Hurricane Center forecast verification report: 2015 hurricane season. NOAA Rep., 69 pp., https:/www.nhc.noaa.gov/verification/pdfs/ Verification_2015.pdf.

Cavallo, S. M., R. D. Torn, C. Snyder, C. Davis, W. Wang, and J. Done, 2013: Evaluation of the Advanced Hurricane WRF Data Assimilation System for the 2009 Atlantic Hurricane Season. Mon. Wea. Rev., 141, 523-541, https://doi.org/10.1175/ MWR-D-12-00139.1.

Chan, J. C., and W. M. Gray, 1982: Tropical cyclone movement and surrounding flow relationships. Mon. Wea. Rev., 110, 1354-1374, https://doi.org/10.1175/1520-0493(1982)110<1354: TCMASF $>2.0 . \mathrm{CO} ; 2$.

Chen, H., D.-L. Zhang, J. Carton, and R. Atlas, 2011: On the rapid intensification of Hurricane Wilma (2005). Part I: Model prediction and structural changes. Wea. Forecasting, 26, 885-901, https://doi.org/10.1175/WAF-D-11-00001.1.

Cione, J. J., and E. W. Uhlhorn, 2003: Sea surface temperature variability in hurricanes: Implications with respect to intensity change. Mon. Wea. Rev., 131, 1783-1796, https://doi.org/ 10.1175//2562.1.

Davis, C. A., and L. F. Bosart, 2004: The TT problem: Forecasting the tropical transition of cyclones. Bull. Amer. Meteor. Soc., 85, 1657-1662, https://doi.org/10.1175/BAMS-85-8-1075.

- , and Coauthors, 2008: Prediction of landfalling hurricanes with the advanced hurricane WRF Model. Mon. Wea. Rev., 136, 1990-2005, https://doi.org/10.1175/2007MWR2085.1.

Donelan, M. A., B. K. Haus, N. Reul, W. J. Plant, M. Stiassnie, H. C. Graber, O. B. Brown, and E. S. Saltzman, 2004: On the limiting aerodynamic roughness of the ocean in very strong winds. Geophys. Res. Lett., 31, L18306, https://doi.org/ 10.1029/2004GL019460. 
Dong, K., and C. J. Neumann, 1986: The relationship between tropical cyclone motion and environmental geostrophic flows. Mon. Wea. Rev., 114, 115-122, https://doi.org/10.1175/15200493(1986)114<0115:TRBTCM > 2.0.CO;2.

Doyle, J., and Coauthors, 2017: A view of tropical cyclones from above: The tropical cyclone intensity experiment. Bull. Amer. Meteor. Soc., 98, 2113-2134, https://doi.org/10.1175/ BAMS-D-16-0055.1.

Dudhia, J., 1989: Numerical study of convection observed during the Winter Monsoon Experiment using a mesoscale two-dimensional model. J. Atmos. Sci., 46, 3077-3107, https://doi.org/10.1175/15200469(1989)046<3077:NSOCOD>2.0.CO;2.

Fischer, M. S., B. H. Tang, K. L. Corbosiero, and C. M. Rozoff, 2018: Normalized convective characteristics of tropical cyclone rapid intensification events in the North Atlantic and eastern North Pacific. Mon. Wea. Rev., 146,1133-1155, https:// doi.org/10.1175/MWR-D-17-0239.1.

Franklin, J. L., 1990: Dropwindsonde observations of the environmental flow of Hurricane Josephine (1984): Relationships to vortex motion. Mon. Wea. Rev., 118, 2732-2744, https://doi.org/ 10.1175/1520-0493(1990)118<2732:DOOTEF $>2.0 . C O ; 2$.

Galarneau, T. J., and C. A. Davis, 2013: Diagnosing forecast errors in tropical cyclone motion. Mon. Wea. Rev., 141, 405-430, https://doi.org/10.1175/MWR-D-12-00071.1.

Gaspari, G., and S. E. Cohn, 1999: Construction of correlation functions in two and three dimensions. Quart. J. Roy. Meteor. Soc., 125, 723-757, https://doi.org/10.1002/qj.49712555417.

George, J. M., and W. M. Gray, 1976: Tropical cyclone motion and surrounding parameter relationships. J. Appl. Meteor., 15, 1252-1264, https://doi.org/10.1175/1520-0450(1976)015<1252: TCMASP $>2.0 . \mathrm{CO} ; 2$

Gray, W. M., 1977: Tropical cyclone motion and steering flow relationships in the western Atlantic and in the western Pacific. Preprints, 11th Tech. Conf. on Hurricanes and Tropical Meteorology, Miami Beach, FL, Amer. Meteor. Soc., 472-477.

Hamill, T. M., J. S. Whitaker, D. T. Kleist, M. Fiorino, and S. G. Benjamin, 2011: Predictions of 2011's tropical cyclones using the GFS and ensemble-based data assimilation methods. Mon. Wea. Rev., 139, 3243-3247, https://doi.org/10.1175/ MWR-D-11-00079.1.

Hanley, D., J. Molinari, and D. Keyser, 2001: A composite study of the interactions between tropical cyclones and uppertropospheric troughs. Mon. Wea. Rev., 129, 2570-2584, https:// doi.org/10.1175/1520-0493(2001)129<2570:ACSOTI>2.0.CO;2.

Holland, G. J., 1983: Tropical cyclone motion: Environmental interaction plus a beta effect. J. Atmos. Sci., 40, 328-342, https:// doi.org/10.1175/1520-0469(1983)040<0328:TCMEIP > 2.0.CO;2.

- 1984: Tropical cyclone motion: A comparison of theory and observation. J. Atmos. Sci., 41, 68-75, https://doi.org/10.1175/ 1520-0469(1984)041<0068:TCMACO > 2.0.CO;2.

Holliday, C. R., and A. H. Thompson, 1979: Climatological characteristics of rapidly intensifying typhoons. Mon. Wea. Rev., 107, 1022-1034, https://doi.org/10.1175/1520-0493(1979)107<1022: CCORIT $>2.0 . \mathrm{CO} ; 2$.

Hong, S.-Y., Y. Noh, and J. Dudhia, 2006: A new vertical diffusion package with an explicit treatment of entrainment processes. Mon. Wea. Rev., 134, 2318-2341, https://doi.org/ 10.1175/MWR3199.1.

Hsiao, L.-F., C.-S. Liou, T.-C. Yeh, Y.-R. Guo, D.-S. Chen, K.-N. Huang, C.-T. Terng, and J.-H. Chen, 2010: A vortex relocation scheme for tropical cyclone initialization in Advanced Research WRF. Mon. Wea. Rev., 138, 3298-3315, https://doi.org/ 10.1175/2010MWR3275.1.
Jones, S. C., 1995: The evolution of vortices in vertical shear. Part I: Initially barotropic vortices. Quart. J. Roy. Meteor. Soc., 121, 821-851, https://doi.org/10.1002/qj.49712152406.

Kain, J. S., and J. M. Fritsch, 1990: A one-dimensional entraining detraining plume model and its application in convective parameterization. J. Atmos. Sci., 47, 2784-2802, https://doi.org/ 10.1175/1520-0469(1990)047<2784:AODEPM>2.0.CO;2.

Kaplan, J., and M. DeMaria, 2003: Lager-scale characteristics of rapidly intensifying tropical cyclones in the north Atlantic basin. Wea. Forecasting, 18, 1093-1108, https://doi.org/10.1175/ 1520-0434(2003)018<1093:LCORIT>2.0.CO;2.

,$- \ldots$, and A. Knaff, 2010: A revised tropical cyclone rapid intensification index for the Atlantic and eastern North Pacific basins. Wea. Forecasting, 25, 220-241, https://doi.org/10.1175/ 2009WAF2222280.1.

Liu, Y., D.-L. Zhang, and M. K. Yau, 1999: A multiscale numerical study of Hurricane Andrew (1992). Part II: Kinematics and innercore structures. Mon. Wea. Rev., 127, 2597-2616, https://doi.org/ 10.1175/1520-0493(1999)127<2597:AMNSOH>2.0.CO;2.

Liu, Z., C. S. Schwartz, C. Snyder, and S.-Y. Ha, 2012: Impact of assimilating AMSU-A radiances on forecasts of 2008 Atlantic tropical cyclones initialized with a limited-area ensemble Kalman filter. Mon. Wea. Rev., 140, 4017-4034, https://doi.org/ 10.1175/MWR-D-12-00083.1.

Lynch, P., 1997: The Dolph-Chebyshev window: A simple optimal filter. Mon. Wea. Rev., 125, 655-660, https://doi.org/10.1175/ 1520-0493(1997)125<0655:TDCWAS $>2.0 . C O ; 2$.

— using a digital filter. Mon. Wea. Rev., 120, 1019-1034, https:// doi.org/10.1175/1520-0493(1992)120<1019:IOTHMU>2.0.CO;2.

Marks, F. D., Jr., R. A. Houze Jr., and J. F. Gamache, 1992: Dual-aircraft investigation of the inner core of Hurricane Norbert. Part I: Kinematic structure. J. Atmos. Sci., 49, 919-942, https://doi.org/ 10.1175/1520-0469(1992)049<0919:DAIOTI >2.0.CO;2.

Mlawer, E. J., S. J. Taubman, P. D. Brown, M. J. Iacono, and S. A. Clough, 1997: Radiative transfer for inhomogeneous atmospheres: RRTM, a validated correlated-k model for the longwave.J. Geophys. Res., 102, 16 663-16 682, https://doi.org/ 10.1029/97JD00237.

Molinari, J., P. Dodge, D. Vollaro, K. L. Corbosiero, and F. Marks, 2006: Mesoscale aspects of the downshear reformation of a tropical cyclone. J. Atmos. Sci., 63, 341-354, https://doi.org/ 10.1175/JAS3591.1.

Nguyen, L. T., and J. Molinari, 2015: Simulation of the downshear reformation of a tropical cyclone. J. Atmos. Sci., 72, 45294551, https://doi.org/10.1175/JAS-D-15-0036.1.

Nystrom, R. G., F. Zhang, E. B. Munsell, S. A. Braun, J. A. Sippel, Y. Weng, and K. Emanuel, 2018: Predictability and dynamics of Hurricane Joaquin (2015) explored through convectionpermitting ensemble sensitivity experiments. J. Atmos. Sci., 75, 401-424, https://doi.org/10.1175/JAS-D-17-0137.1.

Parrish, D. F., and J. C. Derber, 1992: The National Meteorological Center's spectral statistical interpolation analysis system. Mon. Wea. Rev., 120, 1747-1763, https://doi.org/ 10.1175/1520-0493(1992)120<1747:TNMCSS > 2.0.CO;2.

Qin, N., and D.-L. Zhang, 2018: On the extraordinary intensification of Hurricane Patricia (2015). Part I: Numerical experiments. Wea. Forecasting, 33, 1205-1224, https://doi.org/ 10.1175/WAF-D-18-0045.1.

Reasor, P. D., R. F. Rogers, and S. Lorsolo, 2013: Environmental flow impact on tropical cyclone structure diagnosed from airborne Doppler radar composites. Mon. Wea. Rev., 141, 2949-2969, https://doi.org/10.1175/MWR-D-12-00334.1. 
Reynolds, R. W., T. M. Smith, C. Liu, D. B. Chelton, K. S. Casey, and M. G. Schlax, 2007: Daily high-resolution blended analyses for sea surface temperature. J. Climate, 20, 5473-5496, https://doi.org/10.1175/2007JCLI1824.1.

Rios-Berrios, R., R. D. Torn, and C. A. Davis, 2016: An ensemble approach to investigate tropical cyclone intensification in sheared environments. Part I: Katia (2011). J. Atmos. Sci., 73, 71-93, https://doi.org/10.1175/JAS-D-15-0052.1.

—_, C. Davis, and R. Torn, 2018: A hypothesis for the intensification of tropical cyclones under moderate vertical wind shear. J. Atmos. Sci., 75, 4149-4173, https://doi.org/ 10.1175/JAS-D-18-0070.1.

Rogers, R. F., 2010: Convective-scale structure and evolution during a high-resolution simulation of tropical cyclone rapid intensification. J. Atmos. Sci., 67, 44-70, https://doi.org/10.1175/ 2009JAS3122.1.

_ P. D. Reasor, and J. A. Zhang, 2015: Multiscale structure and evolution of Hurricane Earl (2010) during rapid intensification. Mon. Wea. Rev., 143, 536-562, https://doi.org/10.1175/ MWR-D-14-00175.1.

Schwartz, C. S., Z. Liu, X.-Y. Huang, Y.-H. Kuo, and C.-T. Fong, 2013: Comparing limited-area 3DVAR and hybrid variationalensemble data assimilation methods for typhoon track forecasts: Sensitivity to outer loops and vortex relocation. Mon. Wea. Rev., 141, 4350-4372, https://doi.org/10.1175/MWR-D-13-00028.1.

,-- , and -2015 : Sensitivity of limited-area hybrid variational-ensemble analyses and forecasts to ensemble perturbation resolution. Mon. Wea. Rev., 143, 3454-3477, https://doi.org/10.1175/MWR-D-14-00259.1.

Skamarock, W. C., and Coauthors, 2008: A description of the Advanced Research WRF version 3. NCAR Tech. Note NCAR/ TN-475+STR, 113 pp, https://doi.org/10.5065/D68S4MVH.

Stauffer, D. R., and N. L. Seaman, 1990: Use of four-dimensional data assimilation in a limited- area mesoscale model. Part I: Experiments with synoptic-scale data. Mon. Wea. Rev., 118, 1250-1277, https://doi.org/10.1175/1520-0493(1990)118<1250: UOFDDA $>2.0 . \mathrm{CO} ; 2$.

Thompson, G., R. M. Rasmussen, and K. Manning, 2004: Explicit forecasts of winter precipitation using an improved bulk microphysics scheme. Part I: Description and sensitivity analysis. Mon. Wea. Rev., 132, 519-542, https://doi.org/10.1175/15200493(2004)132<0519:EFOWPU>2.0.CO;2.

—, P. R. Field, R. M. Rasmussen, and W. D. Hall, 2008: Explicit forecasts of winter precipitation using an improved bulk microphysics scheme. Part II: Implementation of a new snow parameterization. Mon. Wea. Rev., 136, 5095-5115, https:// doi.org/10.1175/2008MWR2387.1.

Torn, R. D., 2010: Performance of a mesoscale ensemble Kalman filter (EnKF) during the NOAA high-resolution hurricane test. Mon. Wea. Rev., 138, 4375-4392, https://doi.org/10.1175/ 2010MWR3361.1.

_ , G. J. Hakim, and C. Snyder, 2006: Boundary conditions for limited-area ensemble Kalman filters. Mon. Wea. Rev., 134, 2490-2502, https://doi.org/10.1175/MWR3187.1.

— J. S. Whitaker, P. Pegion, T. M. Hamill, and G. J. Hakim, 2015: Diagnosis of the source of GFS medium-range track errors in Hurricane Sandy (2012). Mon. Wea. Rev., 143, 132152, https://doi.org/10.1175/MWR-D-14-00086.1.

— T. J. Elless, P. P. Papin, and C. A. Davis, 2018: Tropical cyclone track sensitivity in deformation steering flow. Mon. Wea. Rev., 146, 3183-3201, https://doi.org/10.1175/MWR-D-18-0153.1.

Velden, C., W. E. Lewis, W. Bresky, D. Stettner, J. Daniels, and S. Wanzong, 2017: Assimilation of high-resolution satellite-derived atmospheric motion vectors: Impact on HWRF forecasts of tropical cyclone track and intensity. Mon. Wea. Rev., 145, 1107-1125, https://doi.org/10.1175/ MWR-D-16-0229.1.

Wang, X., 2011: Application of the WRF hybrid ETKF-3DVAR data assimilation system for hurricane track forecasts. Wea. Forecasting, 26, 868-884, https://doi.org/10.1175/ WAF-D-10-05058.1.

— D. M. Barker, C. Snyder, and T. M. Hamill, 2008a: A hybrid ETKF-3DVAR data assimilation scheme for the WRF Model. Part I: Observing system simulation experiment. Mon. Wea. Rev., 136, 1190-1200, https://doi.org/10.1175/2008mwr2444.1.

,,--- , and $-2008 \mathrm{~b}$ : A hybrid ETKF-3DVAR data assimilation scheme for the WRF Model. Part II: Real observation experiments. Mon. Wea. Rev., 136, 5132-5147, https://doi.org/10.1175/2008MWR2445.1.

Wang, Y., and G. J. Holland, 1996: Tropical cyclone motion and evolution in vertical shear. J. Atmos. Sci., 53, 3313-3332, https:// doi.org/10.1175/1520-0469(1996)053<3313:TCMAEI>2.0.CO;2.

Wu, C.-C., and K. Emanuel, 1995: Potential vorticity diagnostics of hurricane movement. Part I: A case study of Hurricane Bob (1991). Mon. Wea. Rev., 123, 69-92, https://doi.org/10.1175/ 1520-0493(1995)123<0069:PVDOHM > 2.0.CO;2.

_ agnosis of the key factors affecting the motion of Typhoon Sinlaku (2002). Mon. Wea. Rev., 132, 2084-2093, https://doi.org/ 10.1175/1520-0493(2004)132<2084:PVDOTK > 2.0.CO;2.

Wu, T. C., H. Liu, S. Majumdar, C. Velden, and J. Anderson, 2014: Influence of assimilating satellite-derived atmospheric motion vector observations on numerical analyses and forecasts of tropical cyclone track and intensity. Mon. Wea. Rev., 142, 4971, https://doi.org/10.1175/MWR-D-13-00023.1.

—, C. Velden, S. Majumdar, H. Liu, and J. Anderson, 2015: Understanding the influence of assimilating subsets of enhanced atmospheric motion vectors on numerical analyses and forecasts of tropical cyclone track and intensity with an ensemble Kalman filter. Mon. Wea. Rev., 143, 2506-2531, https:// doi.org/10.1175/MWR-D-14-00220.1.

Zagrodnik, J. P., and H. Jiang, 2014: Rainfall, convection, and latent heating distributions in rapidly intensifying tropical cyclones. J. Atmos. Sci., 71, 2789-2809, https://doi.org/10.1175/ JAS-D-13-0314.1.

Zhang, X., Y. Li, D.-L. Zhang, and L. Chen, 2018: A 65-year climatology of unusual tracks of tropical cyclones in the vicinity of China's coastal waters. J. Appl. Meteor. Climatol., 57, 155170, https://doi.org/10.1175/JAMC-D-16-0392.1.

Zhu, T., and D.-L. Zhang, 2006: The impact of the storm-induced SST cooling on hurricane intensity. Adv. Atmos. Sci., 23, 14-22, https://doi.org/10.1007/s00376-006-0002-9. 